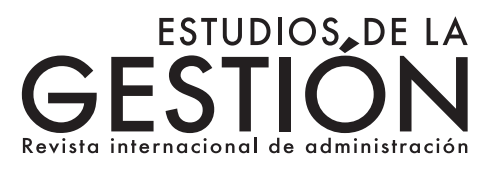

\title{
Rendimiento de la educación en Ecuador
}

\author{
Education performance in Ecuador \\ Rendimento da educação no Equador \\ María Fernanda Lucero \\ Universidad de las Américas (Quito, Ecuador) \\ mariafernanda.lucero@udla.edu.ec
}

DOI: https://doi.org/10.32719/25506641.2019.6.2

Fecha de presentación: 11 de junio de 2019 • Fecha de aceptación: 11 de septiembre de 2019

Artículo de investigación

Licencia Creative Commons

()(1)(9) (2) 


\section{Resumen}

La relación entre educación e ingresos, establecida por la teoría del capital humano, propone tratar la educación como uno de los principales determinantes del nivel de ingresos de los individuos. No obstante, si bien la teoría confirma que la educación ofrece una ventaja para obtener mayores ingresos, a partir del siglo XXI se discuten hipótesis que señalan rendimientos decrecientes en la educación. Bajo este contexto, el objetivo del presente estudio es analizar la relación empírica existente entre el ingreso de personas asalariadas y los niveles de educación, así como la evolución del retorno educativo para el período 2007-2017 en Ecuador. Para su demostración, se emplearon modelos de corte transversal para cada año, utilizando datos de la encuesta nacional de empleo, desempleo y subempleo (ENEMDU) con base en la ecuación de Mincer, estimados mediante la aplicación de diseño muestral. En este escenario, los resultados confirman la ventaja que ofrece la educación en la obtención de ingresos, sin embargo, se concluye que esta ventaja presenta un comportamiento decreciente.

Palabras clave: Rendimiento educativo, mercado laboral, ingresos.

JEL: J31 Nivel y estructura salarial, diferencias salariales por cualificación, formación, ocupación.

\section{Abstract}

The relationship between education and income, established by the human capital theory, proposes to treat education as one of the main determinants of the individuals' level of income. However, although the theory confirms that education offers an advantage to obtain higher incomes, starting from the 21 st century, hypotheses that indicate diminishing returns in education have been discussed. Under this context, the objective of the present study is to analyze the empirical relationship between the salaried people income and education levels, as well as the evolution of the educational return for the period 20072017 in Ecuador. For its demonstration, cross-sectional models were used for each year, using data from the national employment, unemployment and underemployment survey (ENEMDU) based on the Mincer equation, estimated using the sample design application. In this scenario, the results confirm the advantage that education offers in obtaining income, however, it is concluded that this advantage presents a decreasing behavior.

Keywords: Educational performance, labor market, income.

JEL: J31 Salary structure and level, salary differences by qualification, training, occupation.

\section{Resumo}

A relação entre educação e renda, estabelecida pela teoria do capital humano, propõe tratar a educação como um dos principais determinantes do nível de renda dos indivíduos. Não obstante, se por um lado a teoria confirma que a educação oferece uma vantagem para obter maior renda, a partir do século XXI são discutidas hipóteses que indicam rendimentos decrescentes na educação. Sob este contexto, o objetivo do presente estudo é analisar a relação empírica existente entre a renda de pessoas assalariadas e os níveis 
de educação, assim como a evolução do retorno educativo para o período 2007-2017 no Equador. Para sua demonstração, foram empregados modelos de corte transversal para cada ano, utilizando dados da pesquisa nacional de emprego, desemprego e subemprego (ENEMDU) com na equação do Mincer, estimados mediante a aplicação do desenho de amostragem. Neste cenário os resultados, confirmam a vantagem que oferece a educação na obtenção de renda, no entanto, se conclui que esta vantagem apresenta um comportamento decrescente.

Palavras-chave: Rendimento educativo, mercado de trabalho, renda.

JEL: J31 Nível e estrutura salarial, diferenças salariais pela qualificação, ocupação.

\section{Introducción}

L

a educación como eje estratégico para el mejoramiento del capital humano de una sociedad es un tema ampliamente desarrollado en la literatura, por su vínculo estratégico con temas centrales como la desigualdad, crecimiento económico, productividad laboral y pobreza. En la literatura económica, la forma de medir los efectos que tienen los años adicionales de escolaridad sobre el ingreso salarial se conoce como retorno de la educación, y la base para cuantificar este efecto se sustenta en los trabajos propuestos por Mincer (1974), quien plantea que un mayor nivel de educación ayuda al individuo a vincularse al mundo laboral de manera más fácil, y consecuentemente los ingresos percibidos serán mayores en comparación a los que se conseguirían con un nivel de escolaridad inferior.

Al mismo tiempo, resulta importante considerar que, a pesar de que existe evidencia que confirma que el salario de los individuos aumenta con los años acumulados de educación, la estructura del mercado laboral puede influir en los retornos educativos, puesto que obtener cierto nivel de formación no garantiza que los individuos encuentren un trabajo donde las habilidades adquiridas sean empleadas o que sus capacidades se vean reflejadas en la remuneración ofrecida por los empleadores. Tratar de evaluar los rendimientos educativos puede resultar un tema complejo, si bien es cierto, existe un consenso sobre las ventajas que ofrece la educación; sin embargo, durante la última década se ha discutido y presentado evidencia que muestra una tendencia decreciente sobre el retorno económico que ofrece un nivel de educación más alto. Esta discusión sobre los rendimientos educativos plantea varias interrogantes, ya que, a pesar de que se tiene certeza del compor- 
tamiento de la educación en los ingresos, también existe incertidumbre sobre el comportamiento de esa ventaja en el tiempo. Por esta razón, se plantea la pregunta: ¿cuál es el comportamiento de las retribuciones laborales que ofrece el nivel educativo en Ecuador?

Este enfoque espera ser un aporte para discutir los desafíos que podrían significar tener más años de educación formal, el perfil de mano de obra que se está formando, y la calidad de la educación experimentada durante la última década, con miras a alcanzar una, sostener y fomentar la universalización de la educación, fortaleciendo dinámicas laborales que impidan que los rendimientos educativos sean negativos.

Para demostrar la hipótesis, se utilizaron modelos de corte transversal para cada año del período 2007-2017, con los datos de la Encuesta Nacional de Empleo, Subempleo y Desempleo (ENEMDU) realizada por el Instituto Nacional de Estadística y Censos (INEC) del Ecuador, y el modelo de Mincer de 1974, corregido mediante diseño muestral, que constituye la base de la estimación; adicionalmente, se estiman modelos complementarios con ajustes adicionales, incluyendo crecimiento y productividad, con la finalidad de superar la restricción de estado estacionario del modelo y robustecer los resultados encontrados.

Los resultados confirman que, efectivamente, mayores niveles de educación ofrecen una ventaja en la obtención de ingresos, sin embargo, se observa que esta ventaja presenta una tendencia decreciente en el tiempo, principalmente en los niveles de secundaria completa y superior universitario. Esto plantea desafíos para diseñar políticas y estrategias de educación que, además de promover el acceso al sistema educativo, incorporen mejoras en la calidad y se ajusten a la dinámica del mercado laboral estos tres componentes: acceso, calidad y dinámica laboral, los cuales deben consolidar un círculo virtuoso para mejorar las oportunidades laborales y la calidad de vida de la población.

Este estudio consta de cuatro apartados. El marco teórico refleja los principales postulados de la teoría del capital humano, así como las hipótesis planteadas a la reducción de los retornos de la educación; el segundo apartado analiza la evolución de la educación y el comportamiento del mercado laboral ecuatoriano; después se presenta la metodología del modelo aplicado para la comprobación de la hipótesis, y pruebas posestimación que validan 
los resultados, así como el análisis y los principales hallazgos; finalmente, se exponen las conclusiones y recomendaciones.

\section{Marco teórico}

\section{Teoría del capital humano y determinantes del ingreso}

La teoría del capital humano constituye uno de los puntos de partida más importantes para posicionar a la educación como uno de los determinantes para impulsar el crecimiento económico, acceso al mercado laboral y adquisición de capacidades y habilidades que determinen los ingresos (Oroval y Escardibul 1998). El origen del concepto del capital humano empieza a ser discutido en obras de autores clásicos, quienes a pesar de no mencionar directamente el término capital humano, destacaron la relevancia de la educación en el mejoramiento de las destrezas y habilidades de los trabajadores, como eje estratégico para alcanzar un mayor nivel de bienestar económico.

En el siglo XVII, Petty (1889) afirmaba que la riqueza de un país dependía fundamentalmente del nivel de conocimiento de sus habitantes: "La riqueza del reino se puede aumentar estableciendo por primera vez al saber como referencia al comercio" (190). Un siglo más tarde, Smith (1776) retoma las ideas desarrolladas por Petty y destaca la importancia de la especialización y el mejoramiento de las destrezas para generar mayor productividad, planteando la división de trabajo como el camino para mejorar la calidad de mano de obra que los individuos son capaces de producir (Smith 1776-1958). Este planteamiento de la división de trabajo y especialización hizo posible la interconexión de la idea del mejoramiento de las destrezas y productividad, lo que permitió que la educación entrara como protagonista al momento de formar las habilidades de los individuos.

Mill (1885) consideró importante la cualificación de la fuerza de trabajo en la determinación de la riqueza, principalmente por el impacto positivo que tiene el desarrollo de destrezas y formación de los trabajadores en la productividad. De igual forma, Marshall (1890) señaló la importancia de la inversión en educación y el papel preponderante que tiene la familia dentro del desarrollo de las habilidades del individuo. En general, el aporte de estos 
autores clásicos permitió que en los años posteriores se desarrolle la teoría del capital humano.

A mediados del siglo XX, autores como Schultz (1961), Becker (1962) y Mincer (1958) plantearon la teoría del capital humano y argumentaron que existe una relación directa entre destrezas, educación y productividad de los salarios. Adicionalmente, Griliches (1977), Harbinson y Myers (1964), Carnoy (1967) y Blaug (1967) centraron la atención en la educación como insumo de crecimiento y destacaron la relación directa entre educación y productividad. Para Schultz (1960), los adelantos en conocimiento constituyen factores decisivos para el mejoramiento del bienestar económico de la población y replantea que la educación debe entenderse como una inversión en lugar de una forma de consumo: "Propongo tratar la educación como una inversión en el ser humano y tratar sus consecuencias como una forma de capital" (Schultz 1960, 571).

Posteriormente, Becker (1994) define la teoría del capital humano como el conjunto de capacidades productivas que los individuos obtienen mediante la acumulación de conocimientos, y agrega que la educación, además de constituir una inversión, es un costo de oportunidad, puesto que los individuos renuncian, por cierto período de tiempo, a la obtención de ingresos para, en el futuro, obtener salarios más elevados. Así, planteó que las personas que no invierten en educación suelen mantener constante su ingreso (U) conforme avanza la edad, mientras que las personas que han invertido en educación recibirán retribuciones menores durante el período de formación ( $Z$ ) y una retribución más elevada conforme avanza su edad, superando posteriormente el de las personas sin educación (figura 1).

Mincer (1958) formalizó las bases para cuantificar el efecto que ejerce la educación en el aumento de los ingresos. La primera propuesta del autor plantea una transformación de la fórmula del valor presente, como un flujo de beneficios que se reciben por mejorar la formación, lo que constituyó el punto de partida para comprender de manera cuantitativa el retorno obtenido por la formación, y recoger el efecto de la retribución de la educación a través de los años de escolaridad y la tasa de rendimiento. Sin embargo, en esa época no existieron los datos suficientes para sustentar su planteamiento, por lo que simplemente se estableció como un modelo teórico. 
Figura 1

Relación entre ingresos y edad

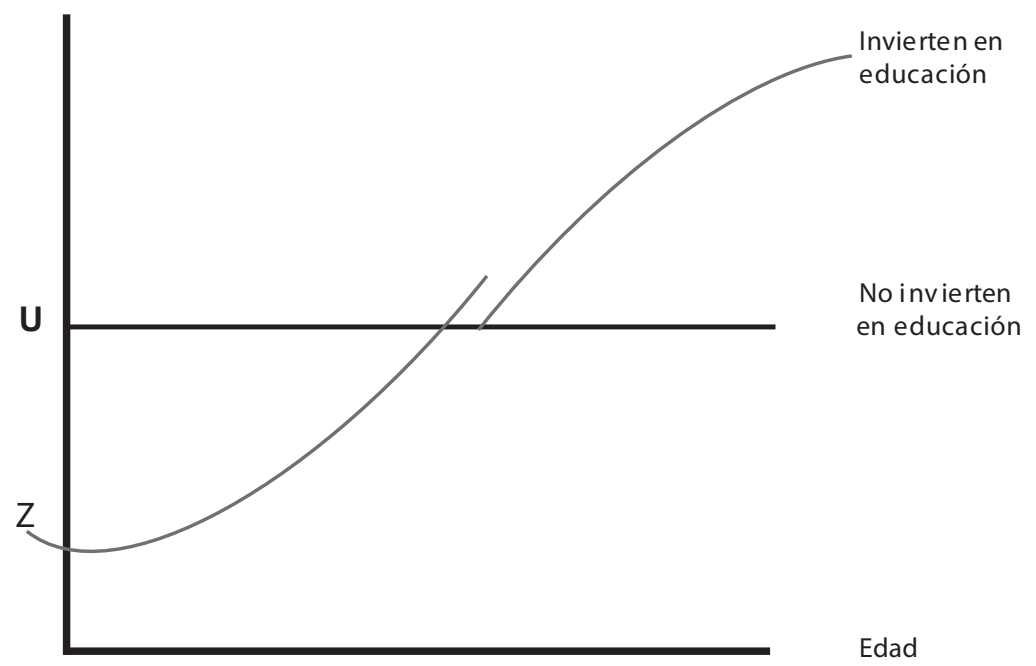

Fuente: Becker (1994).

El principal aporte de Mincer fue plasmado en su obra Schooling, Experience, and Earnings (1974), cuando consideró el conocimiento y las habilidades adquiridas por los individuos a lo largo de su vida y planteó un modelo econométrico lineal que relaciona el nivel de ingresos con la formación adquirida por los individuos y la experiencia obtenida. Este planteamiento metodológico explica las diferencias de los salarios entre los individuos como resultado de la diferencia en inversión educativa (Cardona, Montes, Vásquez, Villegas y Brito 2007).

La ecuación propuesta por Mincer (1974), denominada función de ingresos, explica los ingresos a partir de las variables escolaridad y años de experiencia de los individuos:

$$
\ln (Y)=\beta_{0}+\beta_{1} S+\beta_{2} X+\beta_{3} X^{2}+\varepsilon
$$

Donde $\operatorname{In}(Y)$ representa el logaritmo natural de los ingresos en un período determinado, $S$ los años de educación, $X$ la experiencia, $X^{2}$ la experiencia al 
cuadrado y $\varepsilon$ el término de error. Además, $\beta 0$ representa el intercepto de la ecuación que explica el nivel de ingresos de una persona que no tiene experiencia ni formación.

El planteamiento de los retornos de la educación de Mincer se sustenta a partir de un conjunto de supuestos (Barceinas, Alonso, Raymond y Roig 2001):

a) Los ingresos no contabilizan externalidades, ${ }^{1}$ únicamente muestran la utilidad total de la inversión educativa.

b) La economía no presenta crecimientos salariales ni productivos, es decir, captura únicamente el efecto que ejerce el incremento en el nivel de educación.

c) La escolaridad precede al trabajo, es decir, cuando el individuo se encuentra en etapa de preparación no trabaja.

El estudio de la relación entre ingresos y escolaridad ha llevado en varios trabajos empíricos a probar hipótesis sobre una gran variedad de temas sociales, como por ejemplo distribución del ingreso y discriminación de género; no obstante, la aplicación dominante es la estimación de la tasa de rendimiento de la educación. Por ello, es importante distinguir entre el capital humano (productividad) y las hipótesis de evaluación de los retornos educativos. Por un lado, la teoría del capital humano argumenta que la escolarización imparte habilidades que mejoran la productividad, lo que genera aumentos en los ingresos; mientras que la hipótesis de evaluación sostiene que los empleadores seleccionan trabajadores con calificaciones más altas para reducir el riesgo de contratar a alguien con una menor capacidad de aprendizaje; en este caso, las ganancias más altas pueden no deberse solo a la productividad (Psacharopoulos y Patrinos 2018).

Además de la explicación desarrollada en la teoría del capital humano, hay otra línea de enfoques que agregan nuevas explicaciones para entender las diferencias salariales. Por ejemplo, la teoría credencialista afirma que los factores de demanda, como el puesto de trabajo o el tamaño de la empresa, son los que determinan los niveles de ingresos, y la educación actúa como una herramienta para entrenar a los trabajadores, mas no determina el nivel

1. Las externalidades se refieren a actividades que no están relacionadas con la formación del individuo y que generan ingresos (Pampillón 2001). 
de ingresos (Thurow 1975). Estos hallazgos se sustentan en el supuesto de la presencia de información asimétrica, que sugiere que los empleadores tienen poca información sobre la productividad de los trabajadores, por lo que es necesario que los obreros pongan a la educación como una señal de mayor rendimiento, ya que, en definitiva, son las cualidades tales como la inteligencia, interés y esfuerzo las que determinan verdaderamente el rendimiento del individuo (Barth 1978).

\section{Retornos de la educación}

La teoría del capital humano afirma que la educación es una inversión que permite incrementar los ingresos, es decir, los individuos eligen un nivel de educación hasta el punto que los costos y beneficios se igualan, de manera que el precio asociado a un mayor nivel de educación sea, al menos, compensado por las retribuciones laborales; en otras palabras, a mayores niveles educativos el nivel de ingresos aumenta (Barceinas 1999). No obstante, estudios recientes (Messina y Silva 2017; UNESCO 2013; CEPAL 2015) señalan que el impacto del nivel de formación en los ingresos no es constante. Esta nueva línea de hallazgos aún no constituye una teoría, sin embargo, presenta varias hipótesis para explicar los cambios experimentados en las retribuciones de la educación. Según Perry, Arias, López, Maloney y Serven (2006) y CEPAL (2015), la caída de los retornos de la educación experimentada durante la última década en América Latina puede estar asociada a la tensión entre oferta y demanda laboral ${ }^{2}$ (Paz y Urrutia 2015).

Por el lado de la oferta, el aumento de mano de obra calificada se caracteriza por ser no diversificada, es decir, la formación se concentra en profesiones específicas que terminan saturando el mercado de personas con destrezas y habilidades similares dispuestas a percibir un menor salario (Perry et al. 2006). Esta saturación hace que los individuos no encuentren cabida en el mercado, obligándolos a ubicarse en sectores donde su nivel de formación no es explotado y perciben menores niveles de ingresos. Esto se conoce como efecto de sobreeducación (Acemoglu y Zilibotti 2001) que, a su vez, causa

2. Se entiende por oferta a la cantidad de individuos disponibles en el mercado laboral, y por demanda a la cantidad de trabajadores que las empresas están dispuestas a contratar. 
el incremento del subempleo profesional, entendido como la subutilización de la capacidad productiva de la población, llevando a que los individuos trabajen menos horas y reciban menores ingresos que sus pares profesionales (Yamada 2007). Adicionalmente, el aumento de los años promedio de escolaridad se concentra en los niveles más básicos de formación, lo que significa que muchas personas no continúan con la educación terciaria, dando paso a la generación de gran cantidad de individuos con bajas cualificaciones.

Por el lado de la demanda, el estudio de Messina y Silva (2017) señala a la globalización y al proceso de liberalización comercial como las potenciales fuentes de variación de la demanda laboral. Los importantes cambios tecnológicos que experimentan las empresas se ven traducidos en la automatización de los procesos productivos, lo que a la vez influye en sus requerimientos de mano de obra. Por un lado, existe un pequeño aumento en la demanda de mano de obra altamente cualificada por su complementariedad con la nueva tecnología. Sin embargo, este aumento presenta un lento crecimiento por la paulatina incorporación de la innovación tecnológica, sobre todo en las economías en desarrollo (Perry et al. 2006). Además, el cambio tecnológico se traduce en la automatización de los procesos productivos, lo que ha generado que varios puestos de trabajo asuman tareas rutinarias que pueden ser realizadas por trabajadores menos calificados, lo que provoca un aumento de la demanda de mano de obra menos sofisticada (Azevedo 2013).

La figura 2 resume los efectos de la tensión en el mercado de trabajo expuestos hasta el momento, muestra el crecimiento de la oferta laboral $\left(O_{1}\right)$, por el aumento de los profesionales que ingresan al mercado y un pequeño incremento de la demanda laboral al preferir individuos con menor requerimiento de competencias y la escasa expansión de puestos de trabajo; ambos efectos generan una disminución del salario real $\left(\mathrm{w}_{0} \mathrm{w}_{1}\right)$ que perciben los trabajadores y explica el deterioro en el crecimiento de los ingresos relacionado con el nivel de formación (Yamada 2016).

\section{Evidencia empírica de los rendimientos de la educación}

Existen diversos estudios empíricos, sobre todo en América Latina y el Caribe, que confirman el fenómeno de la disminución de los retornos de la educación: Parodi, Ramírez y Thompson (2017) para República Dominicana; Klapp y Candia (2016) para Chile; y Tarupi (2015) y Rivera (2015) para 
Figura 2

\section{Relación oferta y demanda laboral}

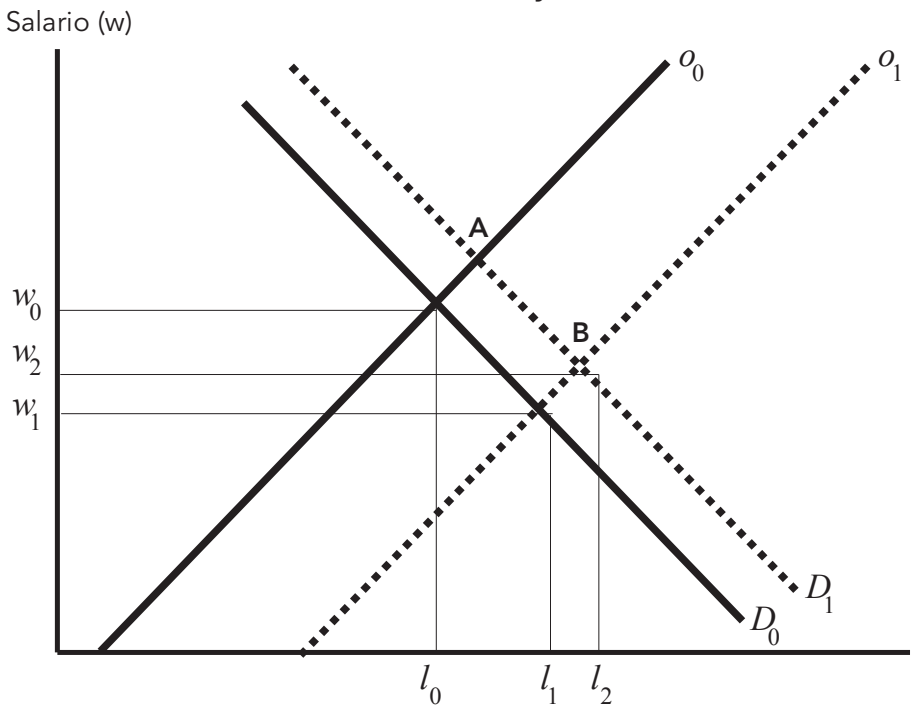

Cantidad de trabajo (l)

Fuente: Williamson (2012).

Ecuador. A continuación, se sistematizan los principales hallazgos de estos estudios.

Rivera (2015) analiza las tasas de retorno de la educación para el caso ecuatoriano con base en la ecuación de Mincer. Este estudio lo realizó con datos de la encuesta nacional de empleo y desempleo urbano y rural (ENEMDUR) para el período 2003-2014. En la estimación el autor utilizó el efecto sheepskin, además de un modelo de Heckman en dos etapas para las brechas salariales. Los resultados de la investigación muestran que el retorno a la educación, durante la última década, se ha mantenido relativamente estable, con una leve tendencia a la baja en los niveles de educación primaria y secundaria. Además, confirma la existencia de una ventaja educativa en niveles educativos más altos. Por otra parte, Tarupi (2015) también realiza un estudio basado en la ecuación de Mincer para Ecuador, en donde obtiene que los niveles de educación secundaria presentan una tendencia decreciente, mientras que los niveles de educación superior presentan una tendencia creciente. 
Parodi, Ramírez y Thompson (2017) encuentran que, para el período 2000-2015, en República Dominicana la inversión en educación, si bien ofrece ventajas para mejorar los ingresos, esta disminuye. Por ejemplo, un año más de educación universitaria está asociada con una tasa de rendimiento ocho veces mayor que la de primaria y cuatro veces mayor a la de secundaria. Sin embargo, la ventaja que ofrece la educación está cayendo, sobre todo en la educación secundaria, con un decrecimiento aproximado de $2,9 \%$, seguido por educación primaria con $1 \%$, y una reducción de $0,5 \%$ para estudios universitarios. La metodología utilizada en este trabajo emplea estimaciones econométricas de corte trasversal a partir de la ecuación de Mincer, incluyendo variables control que capturan las características de los individuos como sexo, área, edad, estado civil y número de hijos.

De igual forma, Klapp y Candia (2016) aplican la ecuación de Mincer para Chile, en un modelo de corte transversal y cohortes sintéticos para los años comprendidos entre 1965 y 2015, y encuentran que al comparar el rendimiento educativo durante este período en cada nivel educativo, el retorno de la educación presenta una caída en el tiempo asociada con la cobertura educativa. Los resultados confirman una disminución en el premio o retorno a la educación en cada uno de los niveles, con mayor impacto para los niveles de educación primaria.

De esta manera, los estudios confirman que, si bien la educación genera una ventaja para tener mayores ingresos, esta ventaja se ha reducido durante las últimas décadas. Esta investigación empírica busca comprobar que este fenómeno se observa también en el caso ecuatoriano para el período más reciente 2007-2017, a través de un análisis más profundo al incluir productividad y crecimiento dentro de los modelos, con la finalidad de mitigar las debilidades que presenta el modelo original de Mincer, y a su vez obtener resultados más cercanos a la realidad. De esta manera, existen estudios que confirman que el crecimiento económico impacta en la obtención de ingresos. Según Barlevy y Tsiddon (2004) y García y Arranz (2013), encuentran una relación procíclica entre crecimiento económico y salarios, es decir, las fases de expansión se acompañan de aumentos salariales, mientras que en períodos de recesión los salarios caen.

Por otro lado, además del vínculo entre crecimiento y salarios, otras investigaciones demuestran una relación entre productividad e ingresos. Desde 
el enfoque microeconómico, la productividad de trabajo depende fundamentalmente del nivel de cualificación de los trabajadores y de la tecnología utilizada, por lo que las diferencias en la productividad del trabajo terminan manifestando un efecto positivo en la demanda de trabajo, lo que provoca que el salario aumente. En otras palabras, existe una relación positiva entre productividad y salarios (Rodríguez y Castillo 2009), razón por la cual constituye también un determinante importante dentro de los ingresos.

De igual manera, existen corrientes del pensamiento que sostienen que el capital humano es un factor determinante de la productividad laboral (Marshall 1890), ya que muestran que existe una fuerte relación entre educación, capacitación laboral y productividad. De esta manera, un aumento de la productividad laboral presenta una relación positiva con mayores ingresos, debido a que el fomento de la productividad genera mayor valor agregado al trabajador, y así el individuo puede obtener un mayor nivel de salario, porque las empresas estarían dispuestas a ofrecer mayores remuneraciones por su eficiencia operativa (Cunningham et al. 2016).

La presente investigación busca conglomerar los diferentes factores que afectan a los ingresos, en conjunto con el modelo de Mincer, para determinar con mayor certeza el rendimiento de la educación en Ecuador para el período comprendido entre 2007 y 2017.

\section{Evolución de la educación en Ecuador}

El gasto público destinado a educación pasó de 4,2 en 2009 al 5\% en 2016. La tendencia creciente también se registra en la región Latinoamérica (figura 3). Sin embargo, la tendencia al alza se revirtió a partir del año 2014 como resultado de una fuerte reducción del presupuesto destinado a la educación, que pasó de USD 3,687 millones en 2014 a USD 3,500 millones, en términos reales en 2015, consistente con el contexto de reducción de los precios del petróleo, que se tradujo en menores ingresos para el Estado, acompañado del cese de la creación y remodelación de un gran número de unidades educativas emblemáticas realizadas en 2014, y que para 2015 ya no se realizaron (EC Ministerio de Educación 2017). 
Figura 3

Gasto público en educación como porcentaje del PIB (2009-2016)

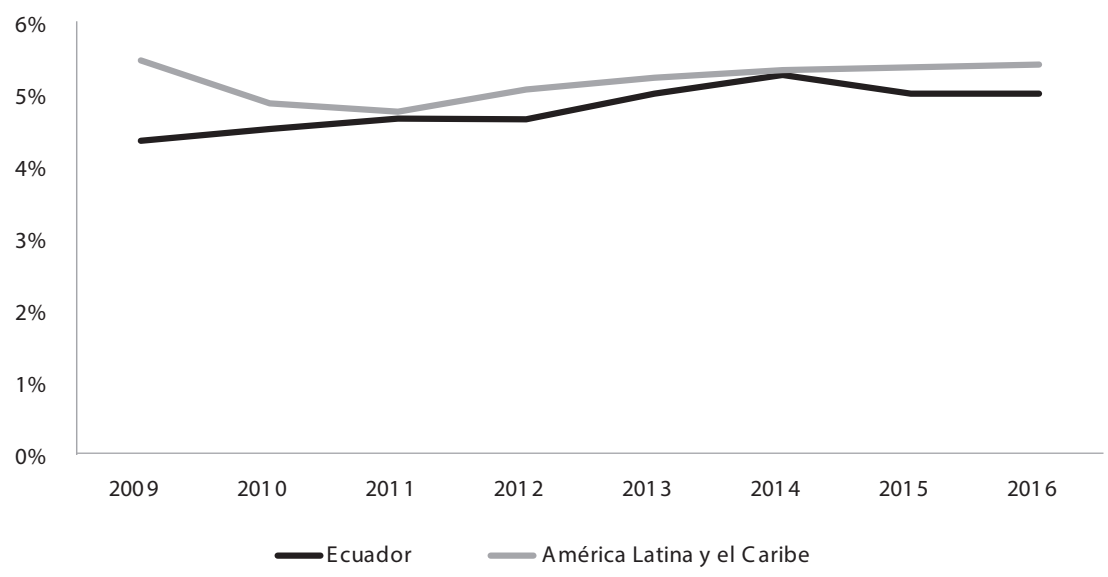

Fuente: UNESCO (2018).

El gasto creciente en educación se acompañó de un incremento de la matrícula neta del sistema educativo, que incluye los niveles de primaria, secundaria y educación superior, acompañada de un incremento en los años de escolaridad promedio que pasó de 9 años en 2006 a 10,1 años en 2016. Esta tendencia también se reporta en América Latina, sin embargo, la evolución de la matrícula neta en Ecuador empezó a registrar un sostenido crecimiento a partir del año 2012, mientras que en América Latina la tendencia creciente se reporta desde inicios de la última década (figura 4).

El salto observado en el número de estudiantes matriculados entre 2012 y 2013 fue resultado de mayores inversiones en construcción y remodelación de centros educativos como mejoras en la gestión administrativa del proceso de matriculación. Se abrieron 18 unidades educativas del milenio con capacidad para atender a aproximadamente 2.000 alumnos, la remodelación de 1.350 establecimientos educativos, y 79 establecimientos en etapas de construcción (27) y planificación (52). Adicionalmente, el plan de matriculación automática llevado a cabo desde el año lectivo 2012-2013 facilitó el proceso del acceso a la educación, razón por la cual entre 2012 y 2013 existió un salto importante (Gestión y Excelencia Educativa 2013). 
Figura 4

\section{Matrícula neta (millones de alumnos (2006-2016)}

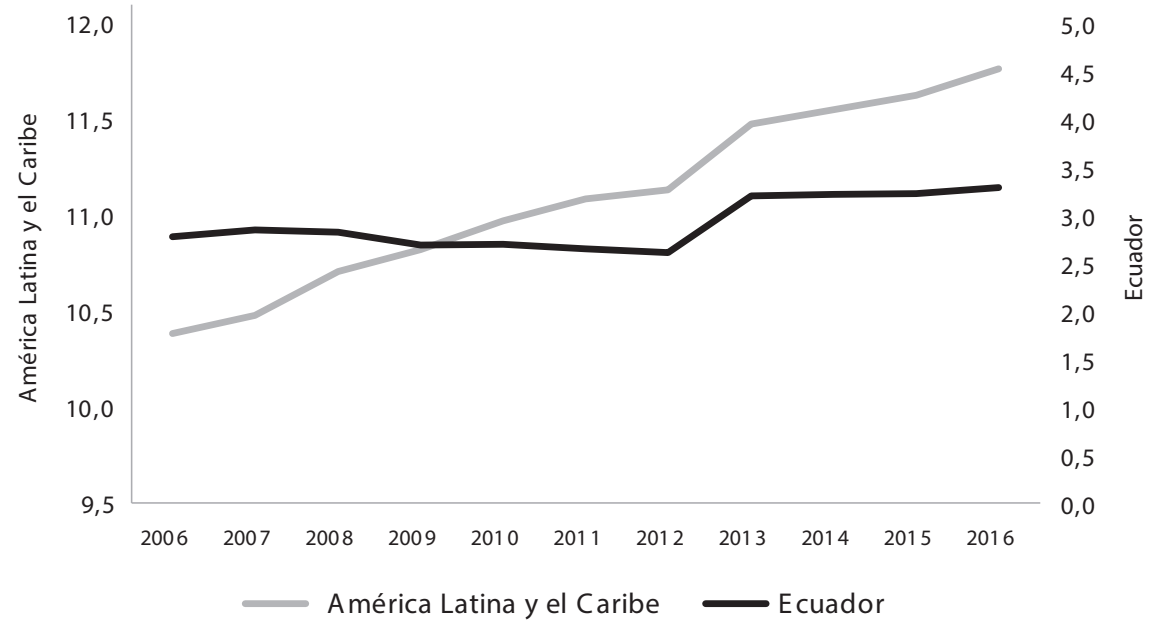

Fuente: UNESCO (2018).

\section{Mercado laboral ecuatoriano}

Para el período de estudio 2007-2017, en el caso del Ecuador, se registró un aumento de la fuerza de trabajo, que pasó de 8,1 a seis millones de trabajadores. Del total de la fuerza de trabajo, ${ }^{3}$ los empleados representan alrededor del $95 \%$, y el $5 \%$ restante son desempleados (figura 5).

Si bien el nivel de desempleo es moderado, puesto que se encuentra por debajo del nivel de desempleo de América Latina (8\%) y es el sexto más bajo de la región, el mercado laboral está compuesto por un alto porcentaje de subempleo, que podría asociarse a empleos de baja calidad. Del total de empleados, aproximadamente el $48 \%$ corresponden a empleo adecuado, ${ }^{4}$ $51,3 \%$ son trabajos no adecuados, que incluyen subempleados, empleados no remunerados y otro empleo no pleno, y el $0,7 \%$ restante está formado por

3. Constituye las personas de 15 años y más que han trabajado al menos una hora a la semana o que no tenían empleo, pero estaban disponibles para trabajar (INEC 2018).

4. Personas que perciben ingresos laborales iguales o superiores al salario mínimo y trabajan 40 horas a la semana (INEC 2018). 
Figura 5

Evolución y composición de la PEA: millones de personas (2007-2017)

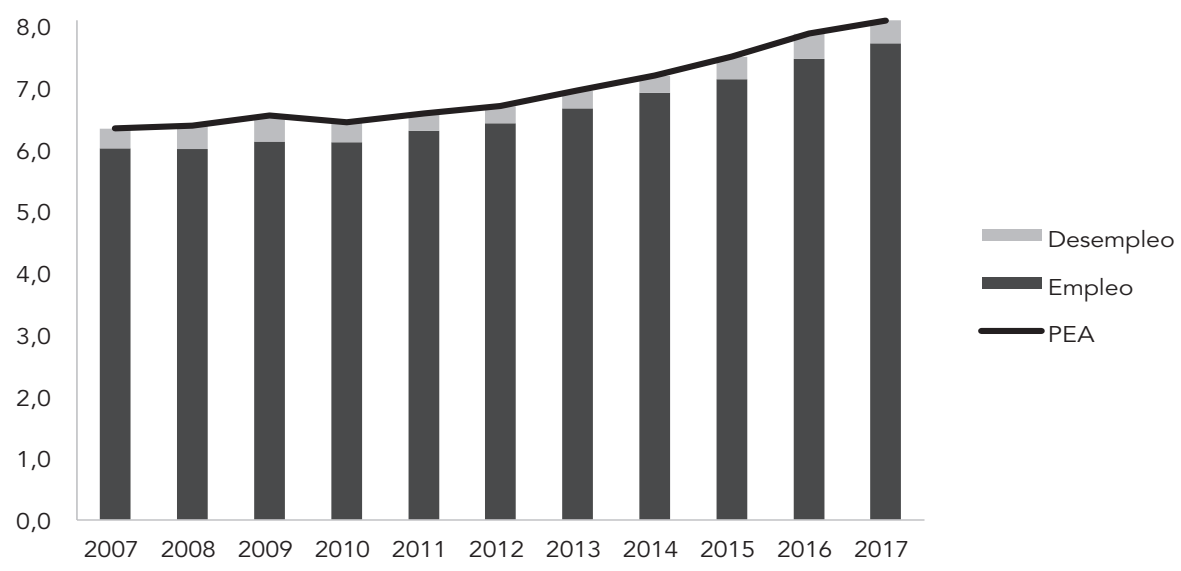

Adaptado de: ENEMDU (2018).

empleo no clasificado (figura 6). Esta estructura de los empleos no muestra los cambios ocurridos durante la última década, lo que podría asociarse con problemas estructurales del empleo en el país.

De igual forma, se registran brechas de acuerdo con el nivel educativo de las personas. En el año 2017 las personas con educación superior y posgrado ganaron entre 6 y 3,24 veces más, respectivamente, que aquellas que no tuvieron ningún nivel de educación. La brecha es menor entre primaria incompleta y completa. En la primera las personas ganaron 1,34 y en la segunda 1,43 veces más en comparación con las personas sin ningún nivel de educación (figura 7). Esto evidencia que la brecha más fuerte para lograr salarios mayores lo pone la educación superior.

A pesar de que la educación ofrece una ventaja para obtener mayores salarios, según los datos del Ecuador, se observa que el crecimiento de los ingresos es menor en los diferentes niveles de educación superior. En otras palabras, en el período 2007-2017, el crecimiento promedio de los ingresos reales de los individuos con educación primaria fue de 3,4\%, mientras que los ingresos de las personas con educación superior y posgrado aumentaron a una tasa menor al 1,9\% (figura 8 ). 
Figura 6

\section{Composición del empleo (2007-2017)}

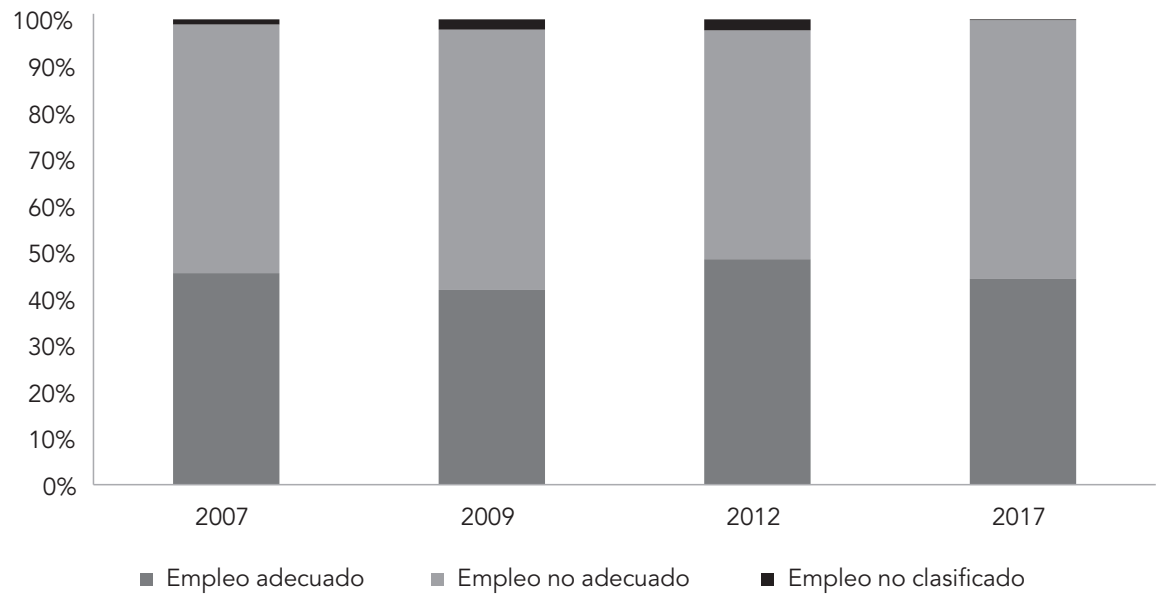

Fuente: ENEMDU (2018).

Figura 7

Ingresos por nivel educativo (2007-2017)

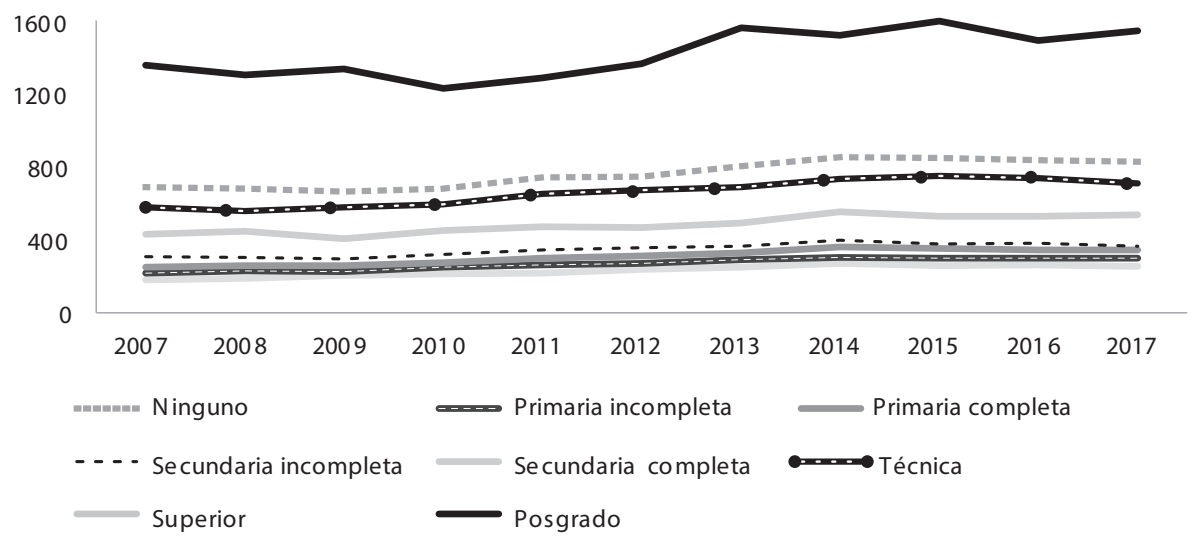

Fuente: INEC (2018). 
Figura 8

Crecimiento promedio de los ingresos por nivel educativo (2007-2017)

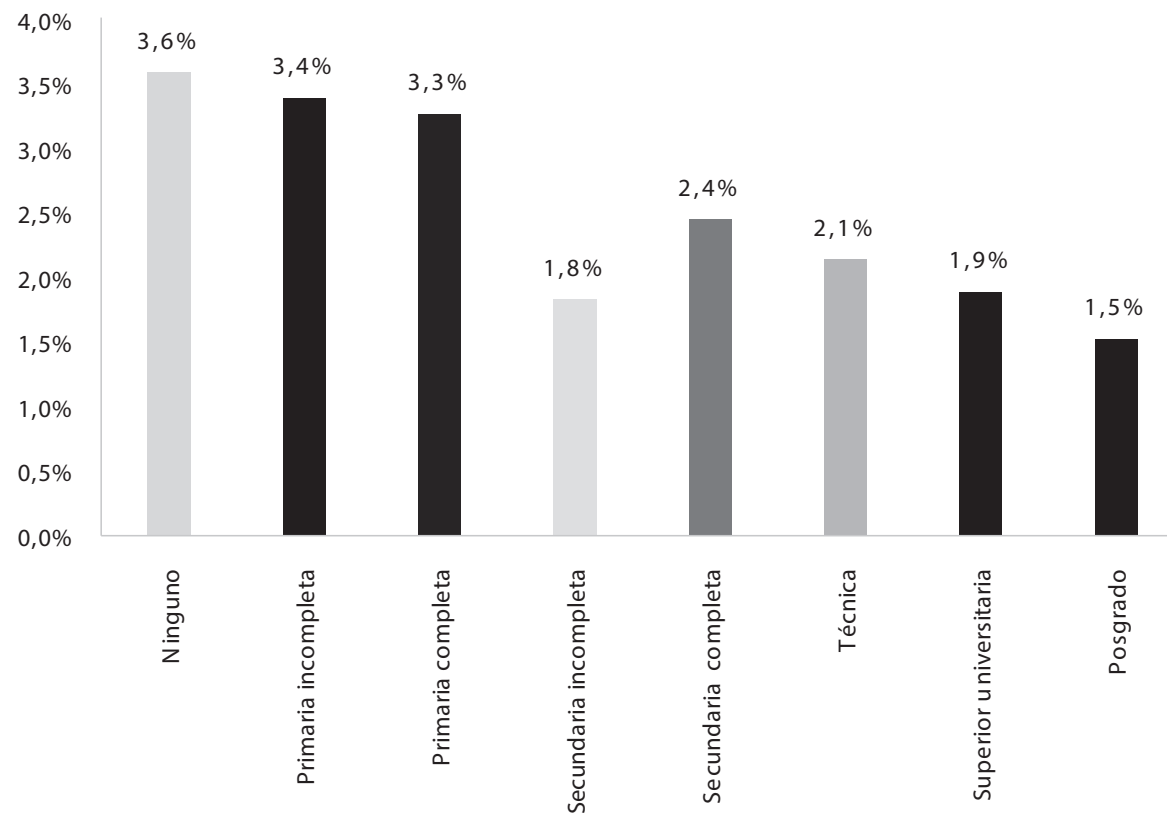

Fuente: INEC (2018).

Adicionalmente, esto se puede ver reflejado en el crecimiento del número de empleados por niveles educativos. Para Ecuador se observa que el mayor incremento del empleo viene dado por individuos con educación técnica y posgrado (figura 9). En efecto, los empleados con educación técnica han aumentado en una tasa promedio de 9,5\% y los empleados con posgrado un $9,4 \%$. Mientras que los individuos con ningún nivel de educación y primaria incompleta disminuyeron en aproximadamente 4,5\%. 
Figura 9

\section{Tasa de crecimiento de empleados por nivel educativo}

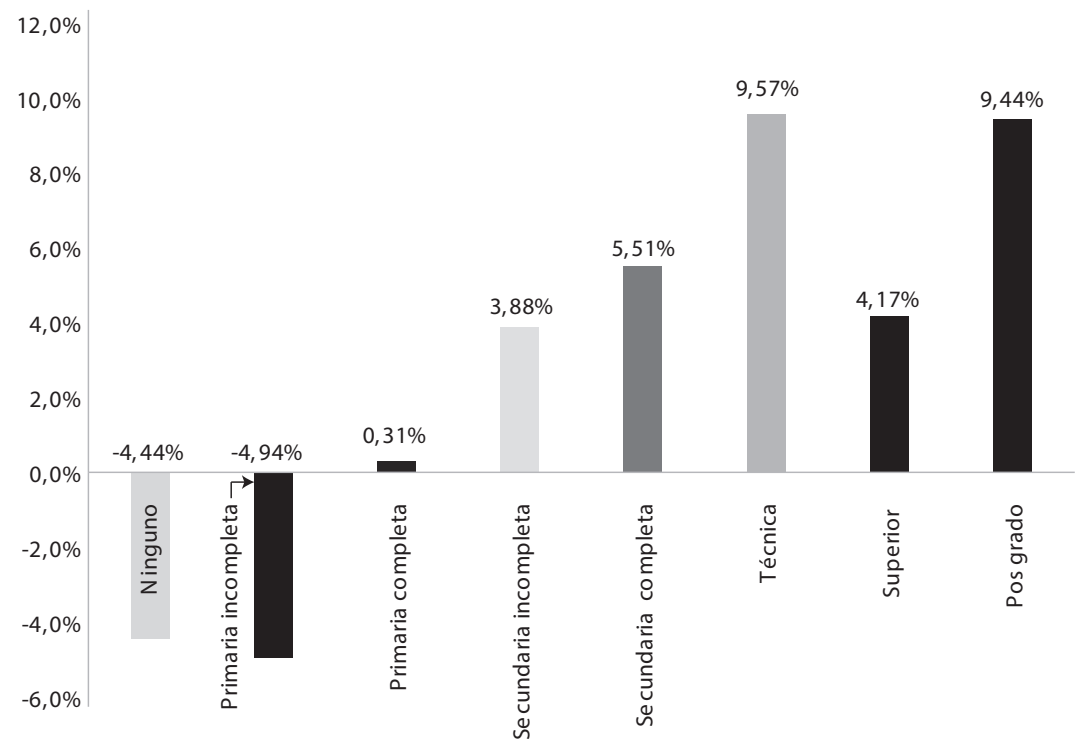

Fuente: ENEMDU (2018).

\section{Perfil de los trabajadores asalariados ecuatorianos}

El perfil de los trabajadores asalariados ecuatorianos, para el período 2007-2017, constituye una parte importante dentro del marco de investigación y se destacan los siguientes hallazgos: a) los asalariados representan más de la mitad de los ocupados del país (57,05\% de la PEA); b) la mayor concentración del empleo asalariado se encuentra en empleos adecuados $(58,7 \%) ; y, c)$ en promedio el ingreso de los asalariados es $20 \%$ más que el salario del resto de ocupados.

Para el período de estudio (2007-2017), en Ecuador se registra un aumento de los empleados, tanto asalariados y resto de ocupados, que pasó de aproximadamente 3,6 millones de trabajadores a 4,5 millones en el caso de trabajadores asalariados y de 2,3 millones a 3,1 millones de trabajadores para el caso del resto de trabajadores ocupados (anexo 1). Del total de los trabajadores empleados, en promedio los asalariados representan el grupo 
mayoritario $(57,5 \%)$ de la PEA, y experimentaron el mayor aumento promedio en el período de estudio: pasaron de 3,6 millones de 2007 a 4,5 millones en 2017 (aumento de 0,9 millones); el resto de nuevos ocupados pasó de 2,3 millones a 3,1 millones (incremento de 0,8 millones); mientras que el resto de ocupados en promedio representa el $37,5 \%$ de la PEA (anexo 1).

El porcentaje de ocupados según nivel educativo para los asalariados ha presentado un mayor crecimiento en primaria completa, ya que creció a un ritmo promedio de 2,98\%; seguido se encuentra la educación superior universitaria y secundaria incompleta, con un crecimiento promedio de 1,92 y $1,49 \%$, respectivamente; a continuación se encuentran los niveles de secundaria, primaria y ningún nivel educativo, con un crecimiento promedio de 1,47, 1,27 y $0,38 \%$. Finalmente se encuentran los niveles de posgrado y educación técnica, con un crecimiento promedio de 1,12 y $0,011 \%$ (anexo 1 ).

De esta manera, aunque se puede observar con mayor claridad la evolución de la oferta de trabajo en Ecuador, no existen datos completos que documenten el comportamiento de la demanda de trabajo para poder caracterizarla y encontrar patrones de comportamiento que permitan dar una visión clara sobre el posible desfase entre oferta y demanda como potencial causante de la caída de los retornos educativos.

\section{Metodología}

En este apartado se explica la metodología empleada para comprobar la hipótesis de que, durante la última década en Ecuador, las retribuciones en términos de ingresos que ofrece el nivel educativo presentan un rendimiento decreciente. Esta metodología parte de los supuestos generales de Mincer (1974), que propone expresar los ingresos en función de la educación y experiencia en el mercado laboral, mediante un modelo econométrico de corte transversal para cada uno de los años del período 2007. Es importante tomar en cuenta que la relación entre ingresos y nivel de educación, que se estimará, no implica necesariamente causalidad, dado que las funciones de ingresos proporcionan retornos privados a la escolarización. El único costo que se tiene en cuenta es el ingreso perdido asociado con asistir a la escuela en lugar de ganar un salario de trabajo (Psacharopoulos y Patrinos 2018); es decir, se omiten los costos 
sociales como la inversión gubernamental en educación o beneficios como la salud.

Con estas limitaciones se estima un modelo que explica los ingresos por ocupación principal de asalariados ${ }^{5}$ (expresado en logaritmo natural), ${ }^{6}$ a partir de las características de formación profesional, general del individuo y ubicación geográfica. La fuente de información es la Encuesta Nacional de Empleo, Subempleo y Desempleo (ENEMDU), para una muestra de alrededor de 20 mil individuos para cada año. Este estudio toma en cuenta una submuestra que incluye únicamente trabajadores mayores a 15 años, con la finalidad de homogeneizar los datos. Adicionalmente, se incluyen únicamente trabajadores asalariados y se omiten los trabajadores independientes, debido a la volatilidad de ingresos que estos presentan (Carrillo 2004). Con este contexto, la estrategia empírica que se utiliza es la estimación de la siguiente ecuación general:

$$
\log (\text { ingreso })=\theta Z_{i}+\alpha W_{i}+\gamma z o n a+u_{i}
$$

En donde, $Z_{i}$ es el vector que hace referencia a las características de formación profesional de los individuos; $W i$ se refiere a las características de perfil de los ocupados; y finalmente la variable zona (urbano o rural). Asimismo, $\theta, \alpha$ representan los vectores de coeficientes asociados a cada variable, y $\gamma$ representa el coeficiente para la variable zona.

Tabla 1

Variables utilizadas en el modelo de corte transversal

\begin{tabular}{|c|l|}
\hline Variable & \multicolumn{1}{c|}{ Descripción } \\
\hline \multicolumn{2}{|c|}{ Variable dependiente } \\
\hline log(ingreso) & $\begin{array}{l}\text { Variable cuantitativa que expresa el ingreso de la ocupación principal, expresado en } \\
\text { términos reales. }\end{array}$ \\
\hline
\end{tabular}

5. Se considera únicamente a individuos mayores de 15 años.

6. Ecuación tradicional de Mincer expresada como un modelo semilogarítmico. 


\section{Variables independientes}

\section{Formación (Vector Zi)}

\begin{tabular}{|c|c|}
\hline \multirow{3}{*}{$\begin{array}{l}\text { Nivel de } \\
\text { educación }\end{array}$} & $\begin{array}{l}\text { Variables dummy }{ }^{* *} \text { que toman el valor de: } \\
\text { 0: no tiene educación (no cursó ningún nivel educativo). }\end{array}$ \\
\hline & $\begin{array}{l}\text { 1: primaria incompleta (aprobado hasta sexto año de educación básica, o quinto } \\
\text { grado de primaria). } \\
\text { 2: primaria completa (aprobado hasta séptimo año de educación básica, o sexto } \\
\text { grado de primaria). } \\
\text { 3: secundaria incompleta (aprobado hasta segundo año de bachillerato o quinto cur- } \\
\text { so de secundaria). } \\
\text { 4: secundaria completa (aprobado hasta tercer año de bachillerato o sexto curso de } \\
\text { secundaria). }\end{array}$ \\
\hline & $\begin{array}{l}\text { 5: técnico. } \\
\text { 6: superior universitario. } \\
\text { 7: posgrado. }\end{array}$ \\
\hline Experiencia & Variable cuantitativa calculada a partir de la propuesta de Atonji y Blank (1999): \\
\hline \multirow[t]{2}{*}{ Idioma } & $\begin{array}{l}\text { Variable dummy que toma el valor de: } \\
\text { 0: solo idioma nativo (solamente habla su lengua de nacimiento, ya sea español } 0 \\
\text { lengua indígena). }\end{array}$ \\
\hline & 1: idioma extranjero (habla su lengua de nacimiento y también otro idioma). \\
\hline \multicolumn{2}{|r|}{ Perfil (Vector Wi) } \\
\hline Sexo & $\begin{array}{l}\text { Variable dummy que toma el valor de: } \\
0: \text { hombre. } \\
\text { 1: mujer. }\end{array}$ \\
\hline Estado civil & $\begin{array}{l}\text { Variable categórica que toma el valor de: } \\
0: \text { casado y unión libre. } \\
\text { 1: otros (incluye separado, divorciado, viudo y soltero). }\end{array}$ \\
\hline \multicolumn{2}{|r|}{ Variable geográfica } \\
\hline Área & $\begin{array}{l}\text { Variable categórica que toma el valor de: } \\
0 \text { : rural. } \\
\text { 1: urbano. }\end{array}$ \\
\hline
\end{tabular}

* Deflactado mediante la utilización de los datos del IPC, año 2007, promedio anual.

** Niveles de educación tomados como variables dummy en contraste con ningún nivel educativo.

*** Para los niveles educativos se realizó la homologación del sistema educativo antiguo que rigió hasta el año 1996 con el actual.

Fuente: ENEMDU (2018). 
Para garantizar que los errores estándar se encuentran correctamente estimados, los modelos tomaron en cuenta el "Diseño maestro de selección muestral para el sistema integrado de encuestas de hogares del INEC Ecuador". El diseño muestral de la ENEMDU es probabilístico-bietápico, y consta de dos fases: unidades primarias de muestreo (UPM), que son los sectores censales utilizados para definir una muestra maestra, y unidades secundarias de muestreo (USM), que son las viviendas seleccionadas dentro de cada UPM (INEC 2014).

Para poder establecer la configuración correcta de la encuesta (ENEMDU), se debe tomar en cuenta la estratificación del marco muestral, que consiste en agrupar las UPM de acuerdo con ciertas similitudes. Así, al tomar en cuenta el diseño muestral de la encuesta, se logra reducir la varianza de los errores de las regresiones estimadas, puesto que los estratos son homogéneos en su interior, lo que, de paso, establece una diferencia fundamental con respecto a las características de los conglomerados, garantizando que las estimaciones sean correctas.

Los resultados del modelo -que se replica para cada año del período de estudio- muestran que todas las variables, con excepción de la categoría primaria incompleta (para los años 2011 a 2017) son significativas al 99\% de confianza. El grado de ajuste o poder predictivo, medido por el coeficiente de determinación, se encuentra entre el 33,5 y $40 \%$ (tabla 2). 


\begin{tabular}{|c|c|c|c|c|c|c|c|c|c|c|c|c|c|}
\hline & స్ & & & $\begin{array}{l}\text { ठ } \\
\text { O }\end{array}$ & ${\stackrel{\infty}{\sigma^{*}}}_{*}^{*}$ & $\begin{array}{l}\tilde{m}^{*} \\
\sigma_{0}^{*}\end{array}$ & 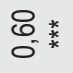 & $\check{\delta}_{-*}^{*}$ & $\stackrel{ㅇ ㅡ ㄹ ~}{*}$ & $\widehat{\sigma}^{*} *$ & $\mathscr{O}_{-*}^{*}$ & 8. & 尺i \\
\hline & ஸั & & & $\begin{array}{l}\text { U } \\
0\end{array}$ & $\tilde{E}^{-*}$ & $\mathscr{m}_{\tilde{m}^{*}}^{*}$ & 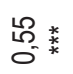 & $\bar{\sigma}^{*}$ & $\stackrel{\infty}{\stackrel{*}{*}}$ & $\underset{*}{*}$ & $\begin{array}{l}\widetilde{O}^{*} \\
\mathrm{O}^{-*}\end{array}$ & $8^{8 * *}$ & $\begin{array}{l}\text { Na } \\
\text { O. }\end{array}$ \\
\hline & ని & & & 응 & $\stackrel{\mathscr{C}^{*}}{\mathrm{\sigma}^{*}}$ & $\begin{array}{l}\text { 우 } \\
\text { ó }\end{array}$ & $\begin{array}{l}\mathbb{8} \\
\Xi^{*}\end{array}$ & $\begin{array}{l}\infty \\
\mathscr{O}_{-}^{*} \\
\sigma^{*}\end{array}$ & 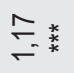 & $\stackrel{L^{2}}{\stackrel{*}{*} *}$ & $\begin{array}{l}\widetilde{O}^{*} \\
\mathrm{O}^{*}\end{array}$ & $\begin{array}{l}8^{*} \\
0^{*}\end{array}$ & $\hat{n}^{*} *$ \\
\hline ํㅗㅇ & ষ্ণ & & & $\begin{array}{l}0 \\
0 \\
0\end{array}$ & 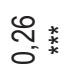 & $\begin{array}{l}\text { 우 } \\
\text { ó }\end{array}$ & $\mathscr{C}_{0}$ * * & 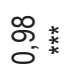 & $\stackrel{\mathscr{O}_{-}^{*}}{\mathrm{O}^{*}}$ & $\underset{*}{*} \underbrace{*}_{*}$ & $\mathscr{O}_{-*}^{*}$ & $\begin{array}{l}8 * \\
\delta^{*} *\end{array}$ & $\tilde{N}^{*} *$ \\
\hline 응 & ঙ্ণ & & & ¿̊ & 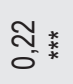 & $\begin{array}{l}\mathscr{O}^{*} \\
\tilde{\sigma}^{*}\end{array}$ & 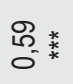 & $\begin{array}{l}\text { D * } \\
\text { o- * * } \\
\text { * }\end{array}$ & $\underset{\text { g }}{\stackrel{*}{*}}$ & $\underset{*}{6}$ * * & $\begin{array}{l}\widetilde{O}^{*} \\
\delta^{*}\end{array}$ & 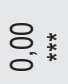 & 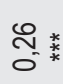 \\
\hline ర్ల & ণั & & & 농 & $\begin{array}{l}\text { ㅈ. } \\
\text { ○'* }\end{array}$ & $\begin{array}{l}\stackrel{n}{m} \\
\tilde{m}^{*}\end{array}$ & $\begin{array}{l}\text { 召 * } \\
0^{*} *\end{array}$ & $\begin{array}{l}\infty \\
\infty \\
0^{-*}\end{array}$ & $\mathrm{~B}_{-}$ & 员* * * & $\begin{array}{l}\mathscr{O}^{*} \\
0^{-*}\end{array}$ & $\begin{array}{l}8 * \\
0^{-*}\end{array}$ & 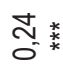 \\
\hline 응 & స్ণ & :등 & $\begin{array}{l}\overline{0} \\
\text { 엉 } \\
\text { 을 }\end{array}$ & $\frac{ \pm}{\sigma^{*}} *$ & $\bar{m}^{-*}$ & $\begin{array}{l}\overline{0} \\
0^{*}\end{array}$ & $\begin{array}{l}\text { Nat } \\
0^{*}\end{array}$ & $\mathscr{8}_{-*}$ & $\stackrel{0}{\rightleftarrows}$ & 怘 & $\tilde{O}^{2}$ * & $\begin{array}{l}8 * * \\
0^{*} *\end{array}$ & $\begin{array}{l}\bar{m} \\
\tilde{o}^{*}\end{array}$ \\
\hline 응 & 웅 & 등 & $\frac{8}{0}$ & $\stackrel{\infty}{\circ}_{0^{*}}^{\infty}$ & $\underset{⿱ \mathbb{Z}}{\stackrel{*}{*}}$ & 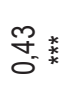 & 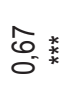 & 合: & $F_{*}$ & $\widehat{\sigma}^{*} *$ & $\begin{array}{l}9 \\
O_{0}^{*} \\
0^{*}\end{array}$ & $\begin{array}{l}\text { 우 } \\
\text { O * }\end{array}$ & 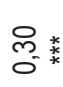 \\
\hline 흥 & 용 & & & $\begin{array}{l}\infty \\
ᄋ_{-}^{\circ}\end{array}$ & $\begin{array}{l}\stackrel{2}{*} \\
\text { on }\end{array}$ & $\begin{array}{l}\mathscr{P} \\
\text { Ó } \\
\text { * }\end{array}$ & $\begin{array}{l}\infty \\
\mathscr{C}_{-*}^{*} \\
\sigma^{*}\end{array}$ & $\stackrel{ㅇ ㅡ ㄹ ~}{*}$ & $\Xi_{*}^{*}$ & 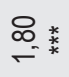 & $\overbrace{}^{2} * *$ & $\begin{array}{l}8 * * \\
\delta^{*} *\end{array}$ & 专 \\
\hline 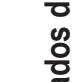 & ஜ̊ & & & $\check{E}_{\sigma^{*}}^{*}$ & $\begin{array}{l}\Re^{*} \\
0^{*}\end{array}$ & 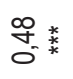 & $\begin{array}{l}\hat{\hat{N}} \\
\mathrm{O}^{*}\end{array}$ & 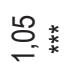 & $\underset{*}{*}$ & $\stackrel{\infty}{\infty} \underset{*}{*}$ & $\begin{array}{l}\mathscr{O}_{-*}^{*} \\
0^{*}\end{array}$ & $\begin{array}{l}\text { 8.* } \\
0^{*} *\end{array}$ & $\begin{array}{l}\text { J * * } \\
\sigma^{*} *\end{array}$ \\
\hline d્ટ & 옹 & & & $\frac{m}{\sigma^{*}}$ & $\bar{m}^{*} *$ & $\begin{array}{l}5 \\
\sum_{0}^{*} \\
0\end{array}$ & $\begin{array}{l}\infty \\
\hat{0}^{-*} \\
n^{*}\end{array}$ & $\mathscr{O}_{-*}^{*}$ & 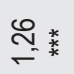 & $\stackrel{0}{\stackrel{0}{*} *}$ & $\begin{array}{l}\mathscr{2} * * \\
0^{-*}\end{array}$ & $\begin{array}{l}8 \\
\text { ㅇ․ } \\
0^{*}\end{array}$ & $\underbrace{0}_{0}$ * * * \\
\hline & 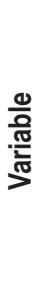 & & & 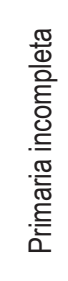 & 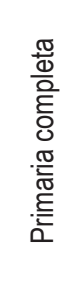 & 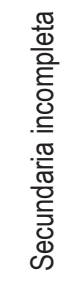 & 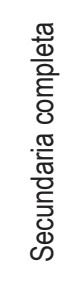 & 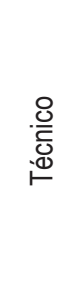 & 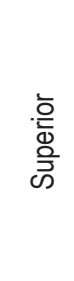 & $\begin{array}{l}\text { 융 } \\
\text { 윰 } \\
\text { ஜ } \\
0\end{array}$ & 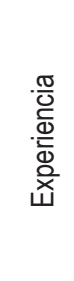 & 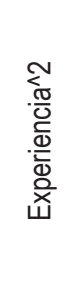 & $\begin{array}{l}\text { 읕 } \\
\text { 음 }\end{array}$ \\
\hline
\end{tabular}




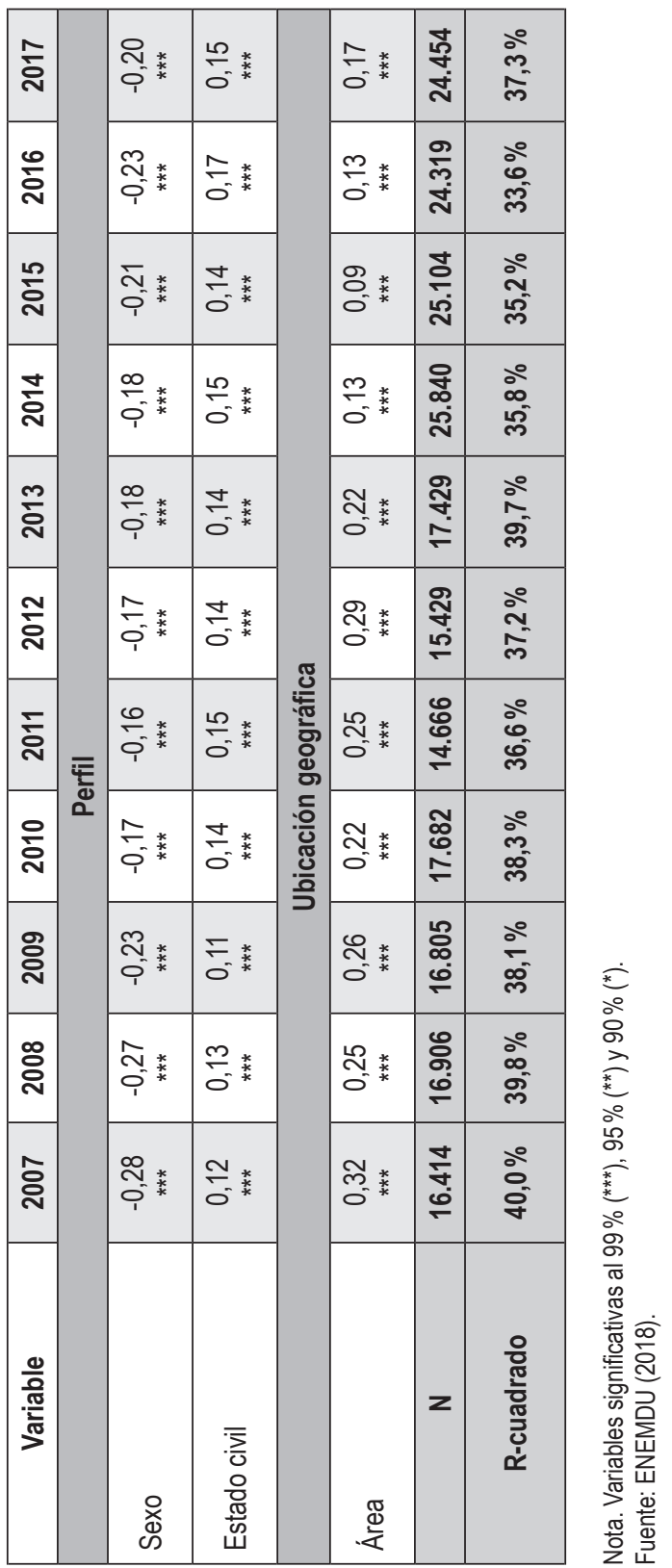




\section{Pruebas posestimación}

Para comprobar la robustez de los coeficientes, se plantea la estimación de modelos complementarios que buscan controlar los efectos de los rendimientos de la educación, incluyendo la dinámica económica y productividad laboral, lo que de alguna forma busca resolver el supuesto de estado estacionario que plantea la ecuación base de Mincer.

Para incorporar la dinámica de la actividad económica se utilizan cuatro modelos complementarios. El primero de ellos incluye el crecimiento económico promedio por rama de actividad de los últimos tres años expresado en términos reales con la finalidad de capturar la dinámica general de la economía en un período de mediano plazo. El segundo modelo contempla el crecimiento anual nacional por rama de actividad en términos reales. El tercer modelo expresa el crecimiento provincial anual por rama de actividad, en términos reales para los años 2008-2016. Finalmente, el cuarto modelo expresa el crecimiento cantonal por rama de actividad expresado en términos reales, de igual forma para los años 2008-2016.

La inclusión de los modelos complementarios con crecimiento cantonal y provincial se realiza con la finalidad de capturar la heterogeneidad del crecimiento interno del país; sin embargo, es importante recalcar que para los modelos complementarios 3 y 4 no se dispone de la suficiente información desagregada por provincia y cantón con el fin de controlar con un criterio igual al modelo complementario 1, razón por la cual estos modelos dan cuenta del impacto del crecimiento de corto plazo para el caso cantonal y provincial.

Adicionalmente, se incorporó la productividad anual por trabajador para cada una de las ramas de actividad laboral, calculado mediante el cociente entre el producto interno bruto y el número de ocupados por rama de actividad, expresado en logaritmo según consta en la tabla 3. Es importante recalcar que los modelos complementarios también fueron estimados considerando el diseño muestral de la ENEMDU. 
Tabla 3

Descripción de modelos complementarios

\begin{tabular}{|c|}
\hline Modelo complementario 1 \\
\hline $\begin{array}{c}\log (\text { ingreso })=\theta Z_{i}+\alpha W_{i}+\gamma z o n a+\emptyset \log (\text { Productividad }) \\
+\partial \text { crecimiento }(\text { Promedionacionaldetresañosatras })+u_{i}\end{array}$ \\
\hline Modelo complementario 2 \\
\hline $\log ($ ingreso $)=\theta Z_{i}+\alpha W_{i}+\gamma z o n a+\emptyset \log ($ Productividad $)+\partial$ crecimiento (anual, nacional $)+u_{i}$ \\
\hline Modelo complementario 3 \\
\hline $\log ($ ingreso $)=\theta Z_{i}+\alpha W_{i}+\gamma$ zona $+\emptyset \log ($ Productividad $)+\partial$ crecimiento $($ anual, nacional $)+u_{i}$ \\
\hline Modelo complementario 4 \\
\hline $\log ($ ingreso $)=\theta Z_{i}+\alpha W_{i}+\gamma z o n a+\emptyset \log ($ Productividad $)+\partial$ crecimiento(anual, cantonal $)+u_{i}$ \\
\hline
\end{tabular}

Elaboración propia.

De donde, $Z i$, Wi y zona son los vectores que hacen referencia a las características de formación profesional, de perfil y de ubicación geográfica, que fueron incluidas en el modelo anterior. Adicionalmente Productividad hace referencia a la productividad laboral, y la variable crecimiento toma en cuenta el crecimiento de la economía. Asimismo, $\theta, \alpha, \gamma, \partial, \phi$ representan los vectores de coeficientes asociados a cada variable.

Los resultados obtenidos en estos modelos, que buscan mitigar las debilidades del modelo de Mincer, arrojaron que la productividad laboral en todos los modelos resultó ser estadísticamente significativa al 99\%, es así que en promedio entre 2007 y 2017 la productividad laboral incrementó el salario en un $6,20 \%$. Por otro lado, la variable crecimiento en el modelo complementario 1 y 2 resultó ser estadísticamente significativa al 99\%. Sin embargo, en los modelos complementarios 3 y 4 la variable de crecimiento (cantonal y provincial) resultó ser no estadísticamente significativa (anexo 4 y 5), por lo que los modelos que se utilizan para confirmar la robustez son: modelo base, modelo complementario 1 (anexo 2), modelo complementario 2 (anexo 3), y modelo complementario 5 (anexo 6), que se detallan a continuación.

Adicionalmente, se realizó la estimación de un quinto modelo (tabla 4) que toma en cuenta las variables incluidas en el modelo base, con la diferen- 
cia de que este modelo se lo realizó sin tomar en cuenta el marco muestral de la ENEMDU.

Tabla 4

Descripción del modelo complementario 5

Modelo complementario 5

$\log ($ ingreso $)=\theta Z_{i}+\alpha W_{i}+\gamma z o n a+\emptyset \log ($ Productividad $)+\partial$ crecimiento $($ anual, cantonal $)+u_{i}$

Elaboración propia.

Para probar su robustez, el modelo complementario 5 se corrió, en el programa, mediante la utilización de errores estándar robustos que permiten modelizar la varianza del error de manera diferente al asignarle un ponderador más pequeño a las varianzas más grandes. Adicionalmente, para garantizar que los errores sigan una distribución normal se realizó la prueba de normalidad de Jarque-Vera y una prueba gráfica, donde se obtuvo que los errores de la muestra siguen una distribución normal (anexo 7).

De esta manera, al realizar una comparación entre los modelos realizados se observa, en primer lugar, que los modelos no muestran cambios en la tendencia, es decir, se mantiene el hallazgo de rendimientos decrecientes; sin embargo, el no controlar las variables por crecimiento y productividad muestra una sobreestimación de los coeficientes en cada nivel educativo (figura 10). Esto confirma que, si bien el modelo de Mincer ayuda a determinar el impacto de la educación en los ingresos, es importante tomar en cuenta las debilidades que este presenta. Estos hallazgos se analizan en la siguiente sección.

\section{Resultados}

Según los resultados obtenidos, se confirma la hipótesis planteada, y se ratifica que en Ecuador, durante la última década, la retribución que ofrece el nivel educativo presenta un rendimiento decreciente. En este sentido, los modelos confirman que, si bien el nivel de educación ofrece una ventaja para tener mayores ingresos, esa ventaja se redujo durante la última década. Así, 
Figura 10

Evolución del coeficiente por nivel de educación para cada modelo

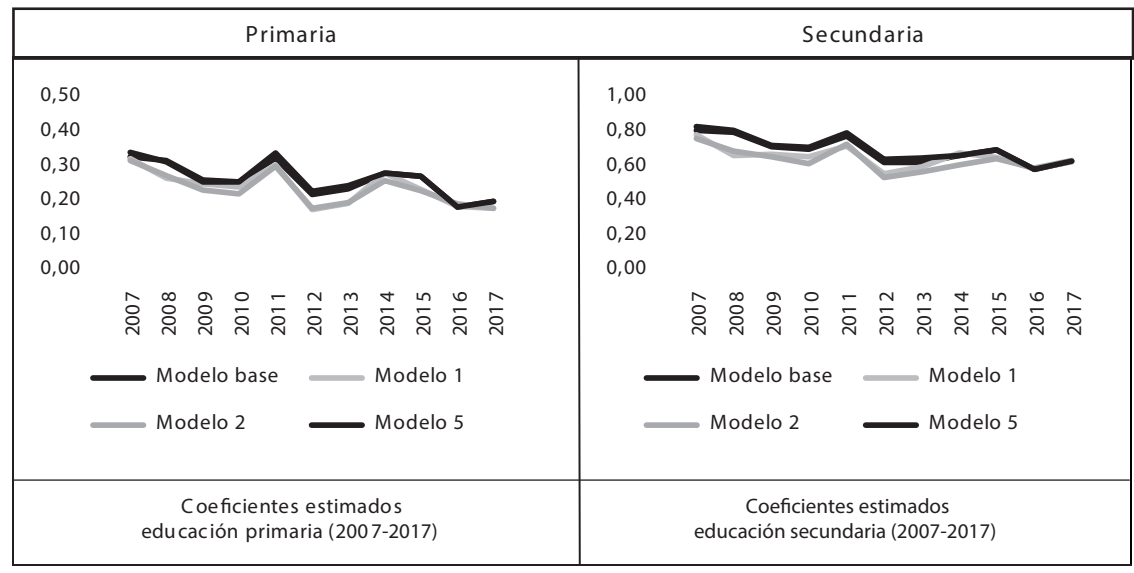

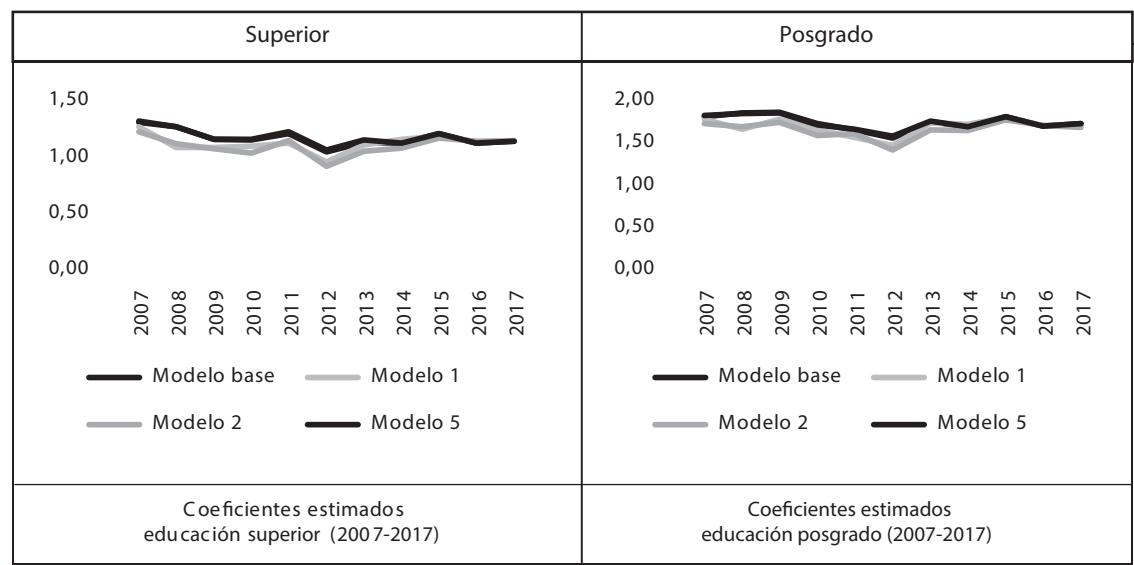

Nota. Los modelos complementarios 3 y 4 no resultaron significativos, por lo que no se los incluye en las figuras. Fuente: ENEMDU (2018).

una persona con primaria completa en promedio gana 24,6\% más que una persona sin educación, mientras que una persona con educación universitaria y posgrado gana 112,6 y 168,3\%, respectivamente, más en relación con una persona que no tiene ningún nivel de educación ${ }^{7}$ (figura 11).

7. Resultados estimados para el modelo base. 
Figura 11

Coeficientes estimados promedio por nivel de educación (2007-2017)

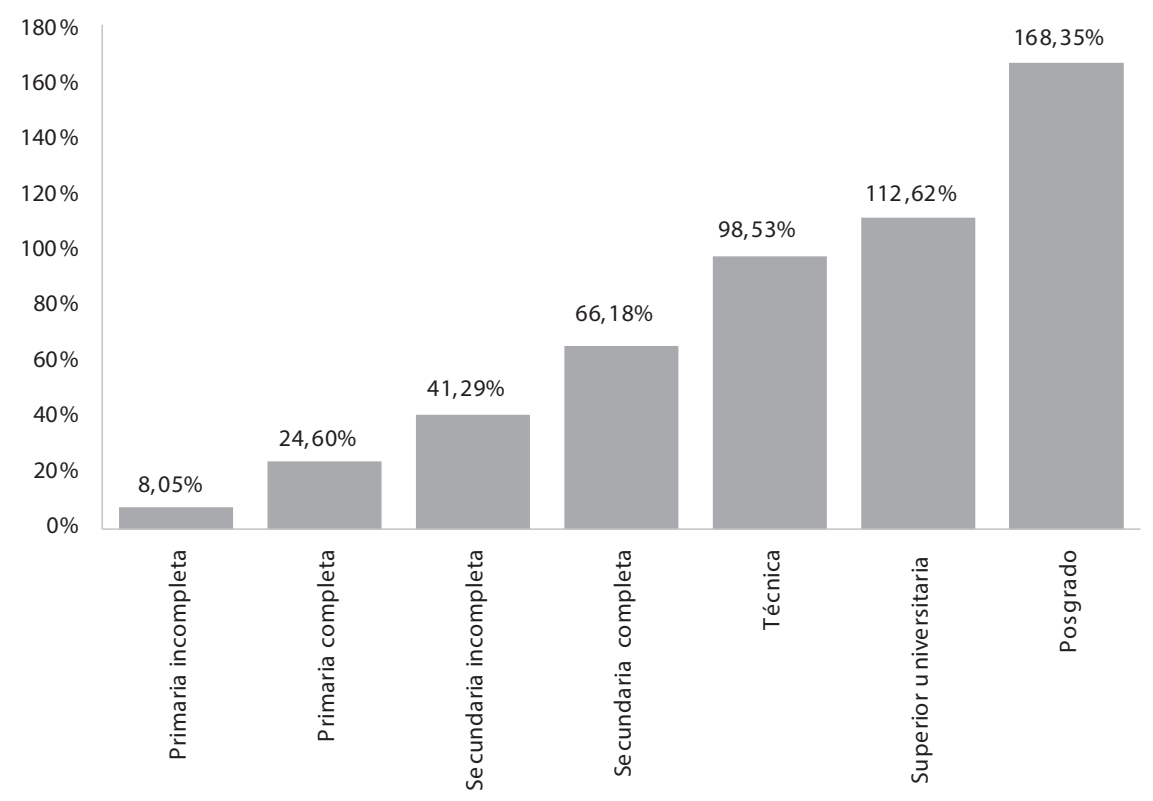

Fuente: adaptado de ENEMDU (2018).

Sin embargo, si bien es cierto que la educación ofrece una ventaja, esta ventaja es cada vez menor. Así, en 2007 si una persona alcanzó estudios primarios completos, en promedio ganaba $31,31 \%$ más que una persona sin estudios, porcentaje que se redujo a $18,32 \%$ en 2017. Del mismo modo que para secundaria completa, en 2007 las personas ganaban 77,96\% más, y para 2017 se redujo a $60 \%$. Este patrón se replica en las personas que alcanzaron educación superior, pasando de 126,3 a 109,8\%. Es así que estos hallazgos evidencian que la educación ofrece una ventaja que cada vez es menor (figura 12). 
Figura 12

\section{Coeficientes estimados nivel de educación (2007-2017)}

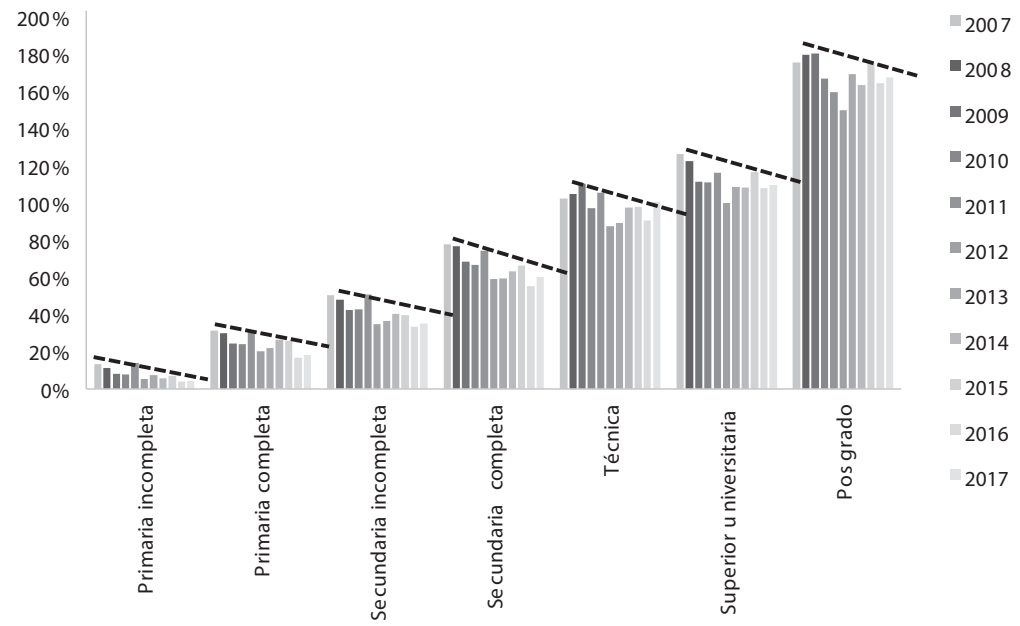

Fuente: ENEMDU 2018.

Además, se observa que los coeficientes caen con mayor magnitud en el nivel de secundaria completa, seguido por educación universitaria. Por ejemplo, en secundaria completa la diferencia de los coeficientes entre 2007 y 2017 es de 17,96 puntos porcentuales, mientras que para educación universitaria es de 16,51 puntos porcentuales. Finalmente, los niveles de educación posgrado y técnica muestran la menor disminución (tabla 5).

Si se analizan los modelos complementarios que confirmaron la robustez de los hallazgos se encuentra que si no se controla por crecimiento y productividad los rendimientos se sobreestiman (tabla 5); sin embargo, a pesar de que la caída del rendimiento es heterogénea, se mantiene que el mayor decrecimiento del rendimiento se da en el nivel de secundaria completa.

Además de los hallazgos sobre el rendimiento de la educación, esta investigación encuentra que hay algunos determinantes que al igual que la educación ofrecen una ventaja para alcanzar mayores salarios. Por ejemplo, el idioma muestra que, en promedio, en la última década el que sabe una lengua extranjera gana un $31,9 \%$ más que aquellos que no la saben. 
Tabla 5

Nivel de reducción del rendimiento en puntos porcentuales (2007-2017)

\begin{tabular}{|l|c|}
\hline \multicolumn{1}{|c|}{ Nivel de educación } & Nivel de reducción del rendimiento \\
\hline Primaria incompleta & $-8,99$ \\
\hline Primaria completa & $-12,99$ \\
\hline Secundaria incompleta & $-15,31$ \\
\hline Secundaria completa & $-17,96$ \\
\hline Técnica & $-2,54$ \\
\hline Superior & $-16,51$ \\
\hline Posgrado & $-8,18$ \\
\hline
\end{tabular}

Fuente: ENEMDU (2018).

De igual forma, la experiencia contribuye a aumentar el salario de los individuos, es decir, en promedio el ingreso aumenta en $2,7 \%$ por cada año más de habilidad. Sin embargo, esta variable no siempre tiene el mismo comportamiento, ya que en promedio presenta una ventaja creciente hasta los 22 años, a partir de este umbral se empieza a registrar una tendencia decreciente (figura 13). En otras palabras, el efecto neto obtenido explica que un año adicional de experiencia aumenta el ingreso en promedio en 2,66\%.

Finalmente, la variable de perfil estado civil y la variable de ubicación geográfica-zona ofrecen una ventaja en el incremento del salario. Así, una persona casada o en unión libre gana en promedio $14 \%$ más que las personas solteras o separadas. Mientras que una persona que vive en el área urbana en promedio gana $21,1 \%$ más que una persona que vive en la zona rural. En cuanto a la variable género, presenta signo negativo, es decir que contribuye a una disminución del salario. Así, las mujeres ganan en promedio 20,7\% menos que los hombres. 
Figura 13

\section{Relación cuadrática ingreso y experiencia}

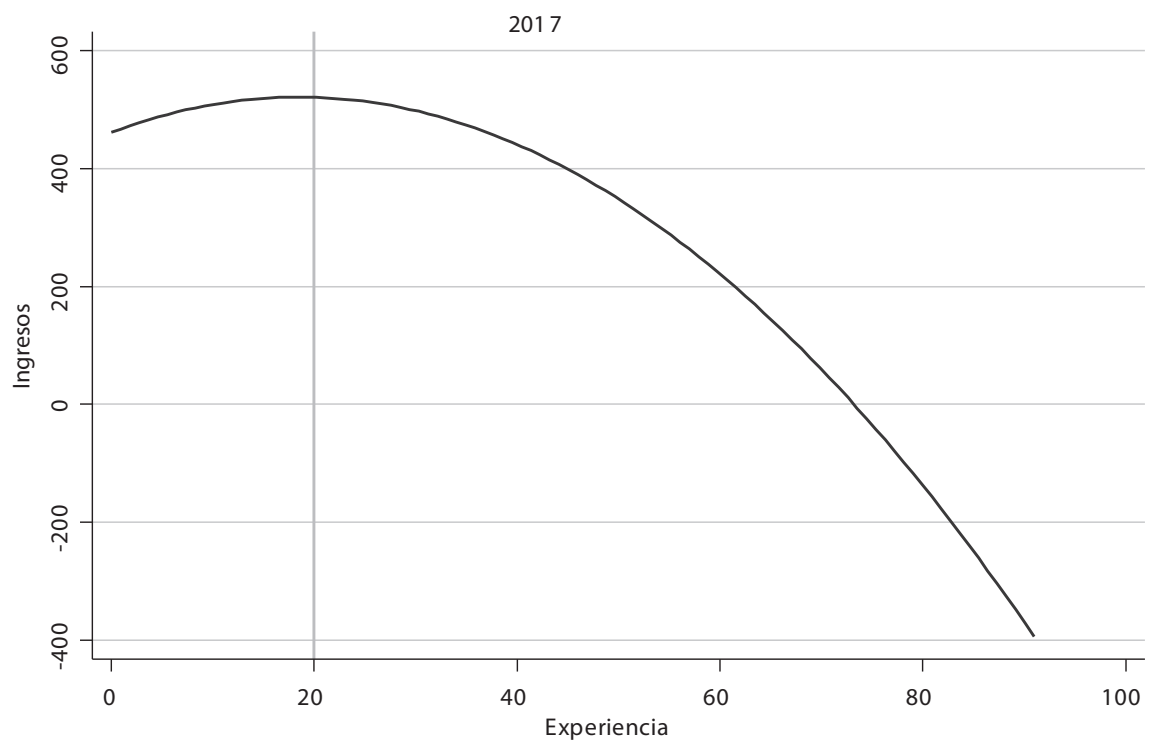

Elaboración propia.

\section{Conclusiones}

La investigación confirma la ventaja que ofrece la educación como fuente para obtener mayores ingresos y revela que, al igual que la tendencia observada en América Latina, las retribuciones que ofrecen los diferentes niveles educativos presentan un rendimiento decreciente.

Los resultados obtenidos a partir de los modelos de corte transversal permiten confirmar ambas situaciones. En primer lugar, se comprueba que, a mayor nivel de educación, los ingresos que obtienen los individuos son mayores. No obstante, esta ventaja se redujo en la última década. Adicionalmente, se observó que independientemente del modelo empleado, ya sea corrigiendo por marco muestral y controlando o no por crecimiento y productividad, la tendencia decreciente de los rendimientos se mantiene. Por otro lado, se obtuvo que el mayor decrecimiento se observa en secundaria 
completa y superior, sin embargo, el foco de esta investigación no es determinar en qué nivel educativo se encuentra el mayor decrecimiento, por lo que no se dispone de la suficiente información que permita confirmar el nivel educativo con mayor impacto.

Por otra parte, se encontró que el ser hombre, vivir en una zona urbana, ser casado o hablar un idioma extranjero constituye una ventaja para obtener mayores ingresos. Por el contrario, el ser mujer, vivir en una zona rural, no conocer un idioma extranjero o ser soltero disminuyen la ventaja de obtener mayores ingresos.

\section{Recomendaciones}

De esta manera, los hallazgos encontrados proporcionan evidencia del impacto cada vez menor de la educación formal. Así, gracias a las hipótesis teóricas planteadas se puede señalar que, si bien los gobiernos han multiplicado sus esfuerzos por llegar a la universalización de la educación, el desafío se plantea en la elaboración de políticas de educación y de mercado laboral que pretendan enfrentar la tensión existente entre oferta y demanda de trabajo. De esta manera, se recomienda elaborar políticas educativas que además de sostener la inversión pública en educación, busquen formar individuos, de acuerdo con las necesidades del mercado.

Adicionalmente, se recomienda focalizar la formación superior o dar prioridad a especializaciones que requiere el mercado, para de esta manera dejar de saturar el mercado y crear nueva oferta de trabajo necesaria para la demanda.

Es importante también atender las desigualdades existentes en el mercado laboral (desigualdad de género, desigualdad territorial) ya que, como se mostró en la investigación, estas diferencias contribuyen a aumentar las brechas existentes en el nivel de ingresos que tienen los individuos.

Del mismo modo, se recomienda elaborar políticas que impulsen el desarrollo empresarial y que tomen en cuenta el empleo que se crea, con la finalidad de generar un mayor número de fuentes de empleo y tener un incremento de la demanda laboral a un ritmo similar al de la oferta. 
Para continuar con esta línea de investigación, se recomienda complementar el presente análisis mediante un estudio de demanda laboral que dé evidencia del comportamiento de la misma dentro del mercado laboral ecuatoriano.

\section{Referencias}

Acemoglu, Daron, y Fabrizzio Zilibotti. 2001. "Productivity Differences". The Quarterly Journal of Economics 116 (2): 563-606. Doi: 10.1162/00335530151144104.

Atonji, Joseph, y Rebecca Blank. 1999. "Race and Gender in the Labor Market". Handbook of Labor Economics, No. 3: 3143-3259. «https://econpapers.repec.org/bookchap/eeelabchp/3-48.htm>.

Azevedo, Pedro, Eugenia Dávalos, Carolina Díaz, Bernando Atuesta y Raúl Castañeda. 2013. "Fifteen Years of Inequality in Latin America: ¿How Have Labor Markets Helped?”. The World Bank. Consulta: abril de 2019. 〈http://bit.ly/32KT7rG〉.

Barceinas, Fernando. 1999. "Función de ingresos y rendimiento de la educación en México". Estudios Económicos 14 (1): 87-127. https://www.jstor.org/stable/40311420〉.

---, Joseph Alonso, José Raymond y José Roig. 2001. "Hipótesis de señalización frente a capital humano". Revista de Economía Aplicada 9 (26): 125-147. «https://dialnet.unirioja. es/servlet/articulo?codigo $=176865$ ).

Barth, Michael. 1978. "Generating Inequality: A Review Article". The Journal of Human Resource 12 (1): 92-102. Doi: 10.2307/145600.

Becker, Gary. 1962. "Investment in Human Capital: A Theoretical Analysis". Journal of Political Economy 70 (5): 9-49. 〈https://www.jstor.org/stable/1829103〉.

---. 1994. Human Capital: A Theoretical and Empirical Analysis with Special Reference to Education. Chicago: University of Chicago Press.

Blaug, Mark. 1967. "The Private and the Social Returns on Investment in Education: Some Results for Great Britain". The Journal of Human Resource 2 (3): 330-346. Doi: $10.2307 / 144838$.

Cardona, Marleny, Isabel Montes, José Vázquez, María Villegas y Tatiana Brito. 2007. "Capital humano: una mirada desde la educación y experiencia laboral". Cuadernos de Investigación 56 (1): 1-31. 〈https://bit.ly/2qbyYcD .

Carnoy, Martin. 1967. "The Rate of Return to Schooling in Latin America". Comparative Education Review 16 (1): 68-86. 〈http://www.jstor.org/stable/1186343〉.

Carrillo, Paúl. 2004. "Las diferencias salariales entre el sector público y privado en el Ecuador". Cuestiones Económicas 20 (2: 3): 166-173. 〈http://bit.ly/2pqZ1PN〉.

Comisión Económica para América Latina y el Caribe (CEPAL). 2015. "Perspectivas económicas de América Latina 2015: educación, competencias e innovación para el desarrollo". Consulta: mayo de 2019. «ttps://bit.ly/31prbI5〉. 
EC Instituto Nacional de Estadística y Censos (INEC). 2014. "Metodología del diseño muestral de la Encuesta Nacional de Empleo y Desempleo ENEMDU". Consulta: mayo de 2019. 〈https://bit.ly/2A7gRtY).

---. 2018. "Encuesta nacional de empleo desempleo y subempleo". Consulta: mayo de 2019. 〈https://bit.ly/2IroH3P〉.

EC Ministerio de Educación. 2017. "Estructuras ocupacionales: salarios mínimos sectoriales y tarifas". Consulta: mayo de 2019. «https://bit.ly/2ITt2OX).

Gestión y Excelencia Educativa. 2013. "Inversión para mejorar la infraestructura educativa". Consulta: mayo de 2019. «https://bit.ly/2Mlk8fv>.

Griliches, Zvi. 1977. "Estimating the Returns to Schooling: Some Econometric Problems". Econometrica 45 (1): 1-22. Doi:10.2307/1913285.

Harbinson, Frederick, y Charles Myers. 1964. "Education, Manpower and Economic Growth". Science 145 (3635): 1-917. Doi: 10.1126/science.145.3635.917.

Marshall, Alfredo. 1890. Principios de economía. Introducción al estudio de esta ciencia. Barcelona: Biblioteca de Cultura Económica XI.

Messina, Julián, y Joanna Silva. 2017. "Desigualdad de ingresos en América Latina". Grupo Banco Mundial. Consulta: abril de 2019. 〈https://bit.ly/2MjQ6Zq〉.

Mill, John S. 1885/2009. Principles of Political Economy. Nueva York: D. Appleton And Company. «ttps://www.gutenberg.org/files/30107/30107-pdf.pdf〉.

Mincer, Jacob. 1958. "Investment in Human Capital and Personal Income Distribution". Journal of Political Economy 66 (4): 281-302. 〈https://www.jstor.org/stable/1827422〉.

---. 1974. Schooling, Experience and Earnings. Nueva York: National Bureau of Economic Research.

Organización de las Naciones Unidas para la Educación, la Ciencia y la Cultura (UNESCO). 2013. "Situación educativa de América Latina y el Caribe. Hacia la educación de calidad para todos al 2015". Consulta: mayo de 2019. 〈https://bit.ly/2IRxwpx〉.

---.2018. "Gasto público en la educación de América Latina". Consulta: mayo de 2019. 〈https://bit.ly/2mE9vtR〉.

---. 2018. Rendir cuentas en el ámbito de la educación: cumplir nuestros compromisos, resumen del informe de seguimiento de la educación en el mundo. Consulta: mayo de 2019. 〈http://bit.ly/35Io29N〉.

Oroval, Esteve, y Oriol Escardibul. 1998. Economía de la educación. Madrid: Ediciones Encuentro.

Pampillón, Rafael. 2001. “¿Qué son las externalidades?”. Diccionario de economía, energía, medio ambiente y cambio climático. Consulta: abril de 2019. «http://bit.ly/2PfTol4〉.

Parodi, Sandro, Indira Ramírez y Jennelle Thompson. 2017. Tasas de retorno de la inversión en educación en la República Dominicana (2000-2015). Washington D. C.: Banco Interamericano de Desarrollo. 
Paz, Peter, y Carlos Urrutia. 2015. "Productividad en el Perú: medición, determinantes e implicancias". Universidad del Pacifico, Lima. Consulta: mayo de 2019. «https://bit.ly/2IWAXLr>.

Perry, Guillermo, Omar Arias, Humberto López, William Maloney y Luis Serven. 2006. "Reducción de la pobreza: círculos virtuosos y círculos viciosos". Banco Mundial. Consulta: abril de 2019. 〈http://reducción-lapobreza-y-crecimientpo-círculosvirtuosos-y-círculos-viciosos/>.

Petty, William. 1899. The Economic Writings. Reino Unido: Cambridge University Press.

Psacharopoulos, George, y Harry Patrinos. 2018. "Returns to Investment in Education. A Decennial Review of the Global Literature". The World Bank. Consulta: mayo de 2019. 〈https://bit.ly/2MjR1Jm〉.

Schultz, Theodore W. 1960. "Capital Formation by Education". Journal of Political Economy 68 (6): 571-83. «ttps://bit.ly/2VNOiuN〉.

---. 1961. "Investment in Human Capital". The American Economic Review 51 (1): 1-17. 〈https://www.jstor.org/stable/1818907〉.

Smith, Adam. 1958. Investigación de la naturaleza y causas de las riquezas de las naciones. (Traducido por Gabriel Franco). Buenos Aires: Biblioteca OMEGALFA.

Thurow, Lester. 1975. Generating Inequality: Mechanisms of Distribution in the U. S. Economy. Londres: Basic Books Inc.

Williamson, Stephen. 2012. Macroeconomía. Madrid: Pearson Education.

Yamada, Gustavo. 2007. "Retornos a la educación superior en el mercado laboral. ¿Vale la pena el esfuerzo?". Economía 31(61): 207-210. 〈https://bit.ly/2VRy8k7〉.

--- 2016. "Educación superior y subempleo profesional: ¿una creciente burbuja mundial?". (PER) Ministerio de Educación. Consulta: mayo de 2019. «http://repositorio.minedu.gob. pe/handle/123456789/5097). 


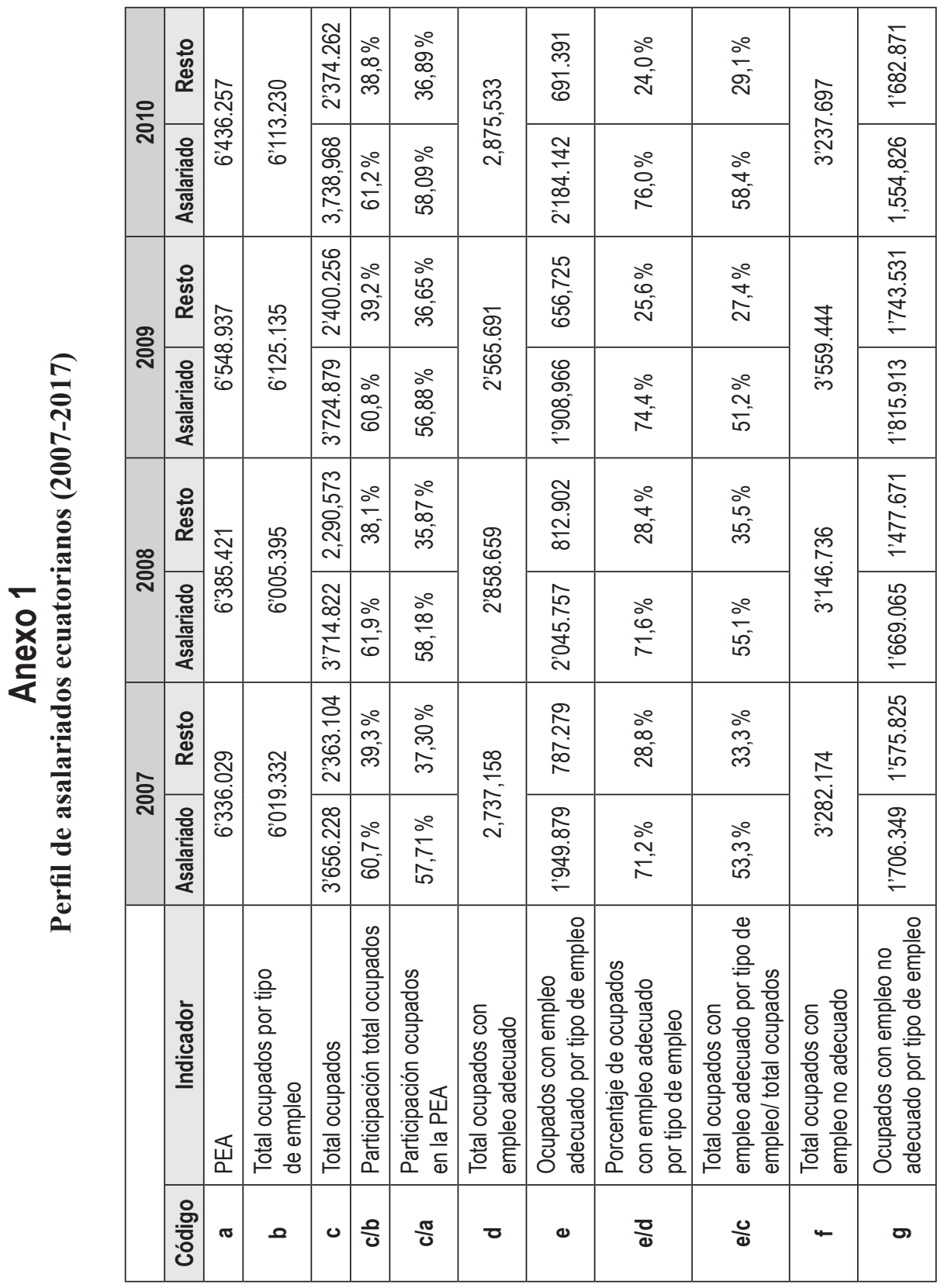




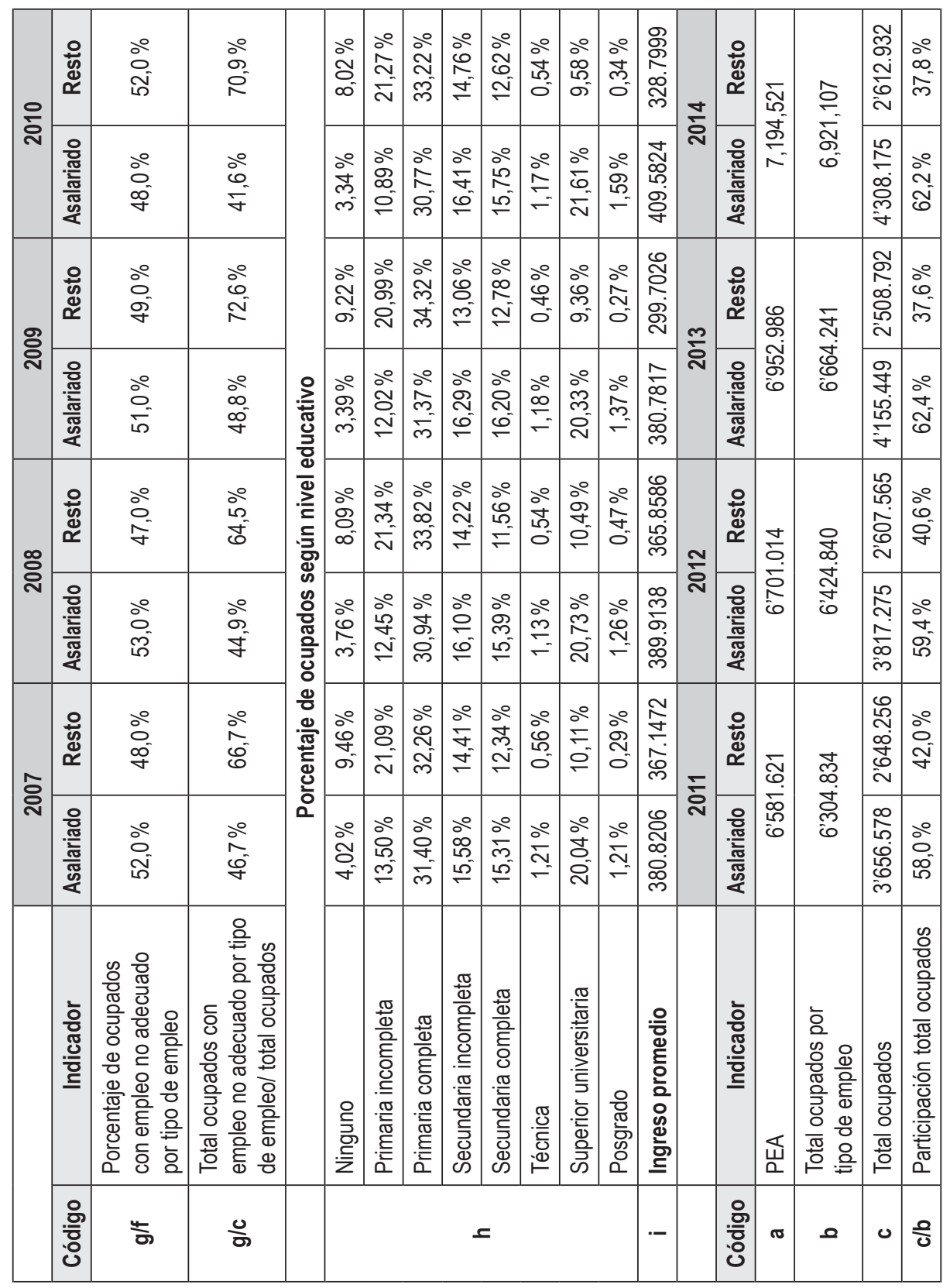




\begin{tabular}{|c|c|c|c|c|c|c|c|c|c|c|}
\hline \multirow{2}{*}{ 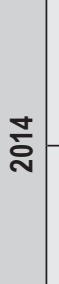 } & 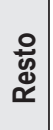 & $\begin{array}{l}\text { ळे } \\
\text { ले } \\
\text { c్ }\end{array}$ & \multirow{2}{*}{ 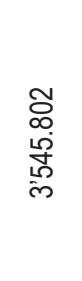 } & $\begin{array}{l}\stackrel{\infty}{\sim} \\
\underset{\sim}{\sim}\end{array}$ & $\begin{array}{l}\stackrel{0}{\circ} \\
\text { ì }\end{array}$ & $\begin{array}{l}\stackrel{0}{0} \\
\infty^{-}\end{array}$ & \multirow{2}{*}{ 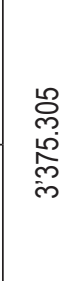 } & 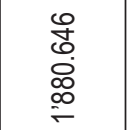 & $\frac{\stackrel{0}{\circ}}{\hat{L}^{\circ}}$ & $\begin{array}{l}\text { 웅 } \\
\text { i }\end{array}$ \\
\hline & 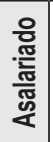 & 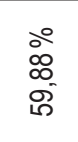 & & $\begin{array}{l}\infty \\
\stackrel{0}{i n} \\
\stackrel{m}{\infty} \\
\stackrel{\infty}{v}\end{array}$ & $\begin{array}{l}\stackrel{0}{0} \\
\text { Oे } \\
\text { ô }\end{array}$ & $\begin{array}{l}\text { o̊ } \\
\text { mo } \\
08\end{array}$ & & 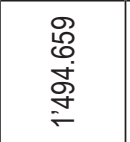 & $\begin{array}{l}\stackrel{0}{0} \\
\text { 守 }\end{array}$ & $\begin{array}{l}\stackrel{0}{N} \\
\text { fín }\end{array}$ \\
\hline \multirow{2}{*}{ ָั } & 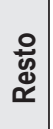 & $\begin{array}{l}\stackrel{0}{0} \\
0 \\
0 \\
00\end{array}$ & \multirow{2}{*}{ 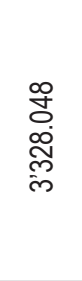 } & 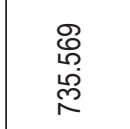 & $\frac{\circ}{\stackrel{N}{N}}$ & $\begin{array}{l}\text { ○े } \\
\text { ळे } \\
\stackrel{N}{2}\end{array}$ & \multirow{2}{*}{ 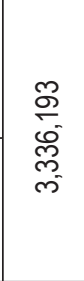 } & $\begin{array}{l}\underset{N}{N} \\
\stackrel{N}{N}\end{array}$ & $\begin{array}{l}\stackrel{0}{0} \\
\underset{\sim}{0}\end{array}$ & $\frac{\stackrel{0}{R}}{\stackrel{2}{2}}$ \\
\hline & 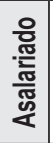 & 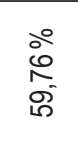 & & 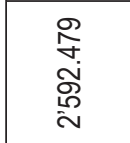 & $\begin{array}{l}\text { 今̊ } \\
\text { م }\end{array}$ & $\begin{array}{l}\stackrel{0}{0} \\
\text { đ̃ }\end{array}$ & & 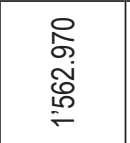 & $\begin{array}{l}\circ \\
\infty \\
\infty \\
0 \\
\dot{f}\end{array}$ & $\begin{array}{l}\text { o̊ } \\
\text { i. } \\
\text { m }\end{array}$ \\
\hline \multirow{2}{*}{ ָัฺ } & 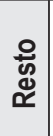 & $\begin{array}{l}\stackrel{\circ}{\circ} \\
\stackrel{5}{\circ} \\
\infty^{\circ}\end{array}$ & \multirow{2}{*}{ 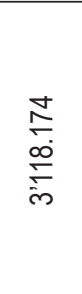 } & $\begin{array}{l}\text { ○ } \\
\infty \\
\dot{\infty}\end{array}$ & $\begin{array}{l}\stackrel{0}{\circ} \\
\stackrel{2}{N}\end{array}$ & $\begin{array}{l}0 \\
\infty \\
\infty \\
0\end{array}$ & \multirow{2}{*}{ 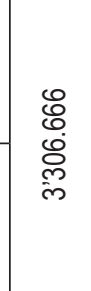 } & 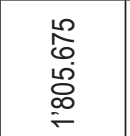 & $\begin{array}{l}80 \\
0 \\
\text { i் }\end{array}$ & $\stackrel{\circ}{\stackrel{\circ}{8}}$ \\
\hline & 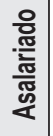 & $\begin{array}{l}\stackrel{0}{0} \\
\hat{\circ} \\
0 \\
0 \\
0\end{array}$ & & 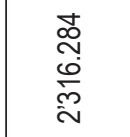 & $\begin{array}{l}\stackrel{0}{0} \\
\stackrel{m}{N}\end{array}$ & $\frac{\circ}{\stackrel{0}{8}}$ & & $\begin{array}{l}\bar{\sigma} \\
\stackrel{8}{\circ} \\
\stackrel{0}{\leftarrow}\end{array}$ & \begin{tabular}{l}
$\circ 0$ \\
\multirow{+}{+}{} \\
of
\end{tabular} & $\begin{array}{l}\text { ○े } \\
\text { ले } \\
\text { ळे }\end{array}$ \\
\hline \multirow{2}{*}{ స్े } & 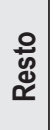 & $\begin{array}{l}\stackrel{\circ}{\circ} \\
\stackrel{+}{+} \\
\stackrel{+}{+}\end{array}$ & \multirow{2}{*}{ 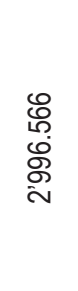 } & 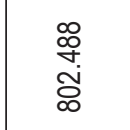 & $\begin{array}{l}0 \\
\infty \\
\infty \\
\infty\end{array}$ & $\begin{array}{l}\stackrel{0}{0} \\
\text { m. } \\
\text { pे }\end{array}$ & \multirow{2}{*}{ 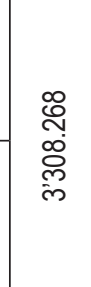 } & \begin{tabular}{l}
$\infty$ \\
0 \\
$\stackrel{0}{0}$ \\
$\infty$ \\
$\infty$ \\
\hdashline
\end{tabular} & $\begin{array}{l}\text { ○ } \\
\infty \\
\infty \\
\infty\end{array}$ & $\frac{\stackrel{0}{0}}{\sigma_{0}^{\circ}}$ \\
\hline & 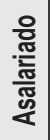 & $\begin{array}{l}\circ 0 \\
80 \\
10 \\
10 \\
10\end{array}$ & & 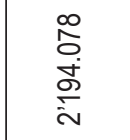 & 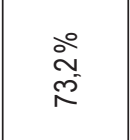 & $\begin{array}{l}\circ \\
\circ \\
8 \\
8\end{array}$ & & 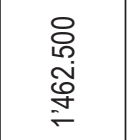 & $\begin{array}{l}\stackrel{0}{\sim} \\
\underset{y}{+}\end{array}$ & $\begin{array}{l}\circ 0 \\
\circ \\
\circ \\
\dot{q}\end{array}$ \\
\hline & 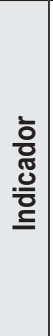 & 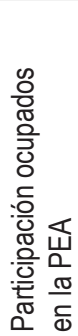 & 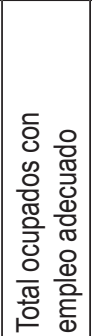 & 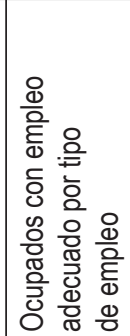 & 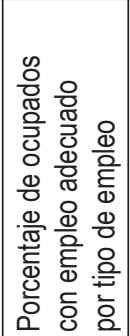 & 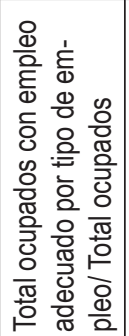 & 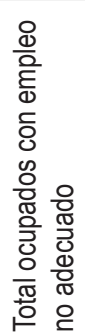 & 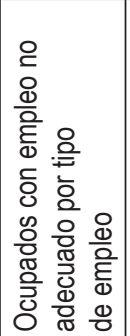 & 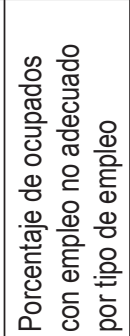 & 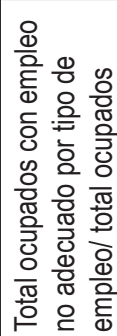 \\
\hline & 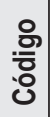 & $\frac{\pi}{0}$ & ర & 0 & $\frac{0}{0}$ & $\frac{0}{0}$ & $\leftarrow$ & סם & $\overleftarrow{5}$ & 응 \\
\hline
\end{tabular}




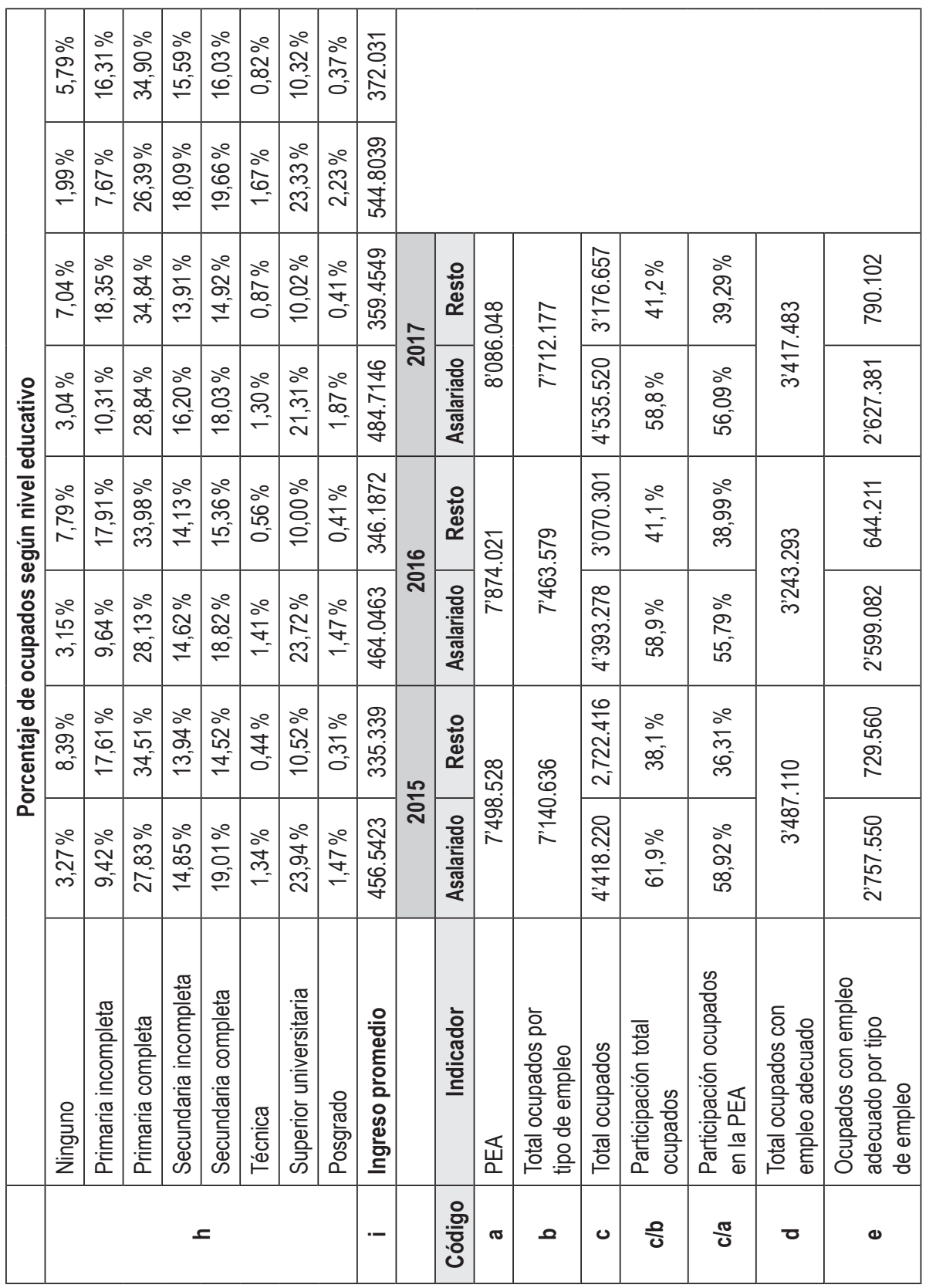




\begin{tabular}{|c|c|c|c|c|c|c|c|c|c|c|c|c|c|c|c|c|}
\hline \multirow{2}{*}{ 동 } & $\frac{0}{\tilde{N}}$ & \begin{tabular}{l} 
o̊ \\
o \\
\multirow{2}{*}{}
\end{tabular} & \multirow{2}{*}{ 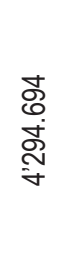 } & 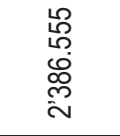 & $\begin{array}{l}00 \\
0 \\
0 \\
0 \\
0\end{array}$ & $\frac{8}{\frac{10}{2}}$ & \multirow{7}{*}{ 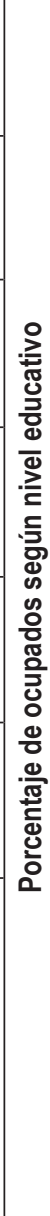 } & $\begin{array}{l}0 \\
0 \\
\infty \\
1 \\
10 \\
10\end{array}$ & $\begin{array}{l}\stackrel{\circ}{\longleftarrow} \\
\stackrel{m}{\sim}\end{array}$ & 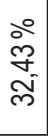 & 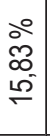 & $\begin{array}{l}00 \\
0 \\
0 \\
\sigma \\
\sigma\end{array}$ & 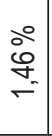 & $\begin{array}{l}\circ 0 \\
0 \\
0 \\
\mp \\
=\end{array}$ & $\mid \begin{array}{c}0 \\
0 \\
10 \\
0 \\
0\end{array}$ & $\begin{array}{l}\text { N } \\
\text { ஸे } \\
\text { ஸ્ }\end{array}$ \\
\hline & $\begin{array}{l}\circ \\
\circ \\
0 \\
0\end{array}$ & $\begin{array}{l}\text { o̊ } \\
\text { ô } \\
\text { in }\end{array}$ & & 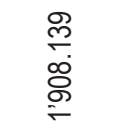 & $\begin{array}{l}\text { o̊ } \\
\dot{y} \\
\text { 寸 }\end{array}$ & 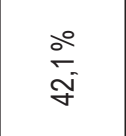 & & $\begin{array}{l}0 \\
\circ \\
\infty \\
\infty \\
-\end{array}$ & 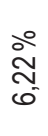 & 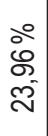 & $\begin{array}{l}\text { ○ீ } \\
\dddot{\infty} \\
\infty \\
\infty\end{array}$ & 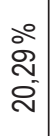 & $\begin{array}{l}00 \\
0 \\
0 \\
ن\end{array}$ & 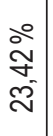 & 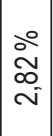 & $\begin{array}{l}\mathscr{S} \\
\text { ণ } \\
\text { ळ্ }\end{array}$ \\
\hline \multirow{2}{*}{$\stackrel{\circ}{\circ}$} & $\begin{array}{l}\circ \\
\text { o̊ } \\
\text { के }\end{array}$ & 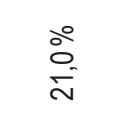 & \multirow{2}{*}{ 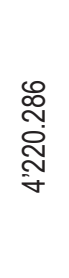 } & 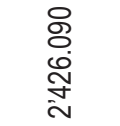 & $\begin{array}{l}\text { i̊ } \\
\text { in } \\
\text { in }\end{array}$ & $\begin{array}{l}0 \\
\vdots \\
0 \\
0\end{array}$ & & 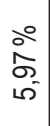 & $\begin{array}{l}\frac{0}{\sigma} \\
\frac{\sigma}{2}\end{array}$ & 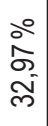 & $\begin{array}{l}\circ 0 \\
\dot{0} \\
m \\
0\end{array}$ & $\frac{\alpha^{\circ}}{\frac{1}{2}}$ & $\begin{array}{l}\stackrel{0}{0} \\
0 \\
\stackrel{m}{=}\end{array}$ & $\begin{array}{l}\stackrel{0}{\sim} \\
\infty \\
\stackrel{-}{\circ}\end{array}$ & $\mid \begin{array}{c}0 \\
0 \\
10 \\
0 \\
0\end{array}$ & 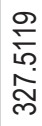 \\
\hline & $\frac{\circ}{\check{\infty}}$ & $\stackrel{\circ}{\stackrel{\circ}{\circ}}$ & & $\begin{array}{l}\mathscr{D} \\
\text { D } \\
\text { D } \\
\stackrel{1}{=}\end{array}$ & $\begin{array}{l}\text { io } \\
\text { in } \\
\text { y }\end{array}$ & $\begin{array}{l}0 \\
\infty \\
\infty \\
\text { o }\end{array}$ & & 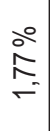 & $\begin{array}{l}\circ 0 \\
80 \\
\varnothing ్ \\
6\end{array}$ & $\begin{array}{l}\stackrel{0}{ } \\
\stackrel{0}{0} \\
\stackrel{\sim}{\sim}\end{array}$ & $\begin{array}{l}\stackrel{0}{\circ} \\
\stackrel{0}{0} \\
\infty^{-}\end{array}$ & $\begin{array}{l}0 \\
\tilde{o} \\
0 \\
0\end{array}$ & \begin{tabular}{l}
00 \\
\multirow{0}{0}{} \\
$\sim$ \\
$\sim$
\end{tabular} & $\begin{array}{l}00 \\
0 \\
0 \\
ஸ ் \\
ஸ\end{array}$ & \begin{tabular}{c}
0 \\
\multirow{0}{0}{} \\
0 \\
$\sim$
\end{tabular} & 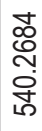 \\
\hline \multirow{2}{*}{ 울 } & $\begin{array}{l}\text { o̊ } \\
\text { Oे } \\
\text { ○ }\end{array}$ & $\begin{array}{l}0 \\
\infty \\
\infty \\
0 \\
\text { co }\end{array}$ & \multirow{2}{*}{ 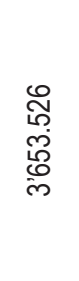 } & $\begin{array}{l}\stackrel{\infty}{\llcorner} \\
\infty \\
\text { Nं } \\
\stackrel{-}{=}\end{array}$ & $\begin{array}{l}00 \\
\text { in } \\
\text { in }\end{array}$ & $\stackrel{\circ}{\stackrel{0}{N}}$ & & $\frac{0}{\stackrel{0}{N}}$ & 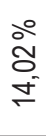 & 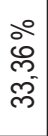 & $\begin{array}{l}\circ 0 \\
\circ \\
60 \\
6\end{array}$ & $\begin{array}{l}0 \\
10 \\
\infty \\
\infty\end{array}$ & \begin{tabular}{l}
$\circ 0$ \\
$\stackrel{0}{\circ}$ \\
\hdashline
\end{tabular} & $\begin{array}{l}\stackrel{0}{ \pm} \\
\stackrel{+}{=}\end{array}$ & $\mid \begin{array}{c}0 \\
0 \\
o \\
0 \\
0\end{array}$ & 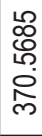 \\
\hline & $\frac{\circ}{\frac{\pi}{2}}$ & 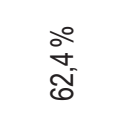 & & $\begin{array}{l}0 \\
0 \\
0 \\
8 \\
6 \\
-\end{array}$ & $\begin{array}{l}\text { o̊ } \\
\text { in } \\
\text { io }\end{array}$ & $\begin{array}{l}0 \\
\dot{0} \\
\hat{m}\end{array}$ & & $\begin{array}{l}0 \\
\infty \\
\infty \\
=\end{array}$ & 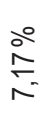 & 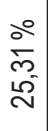 & 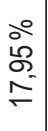 & 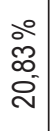 & $\frac{\stackrel{0}{2}}{\Sigma}$ & $\begin{array}{l}00 \\
i \\
\tilde{D} \\
\tilde{N}^{-}\end{array}$ & $\frac{0}{0}$ & 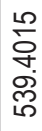 \\
\hline & 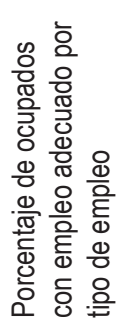 & 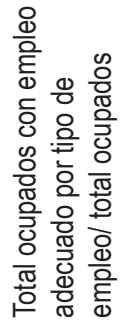 & 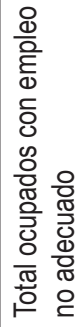 & 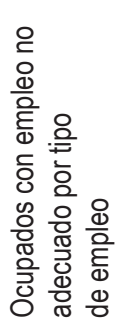 & 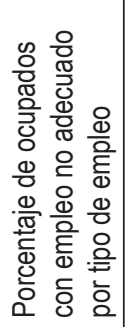 & 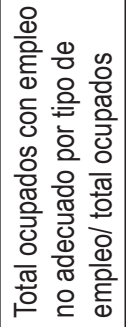 & & 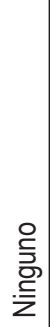 & 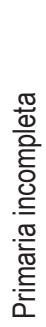 & 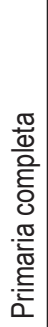 & 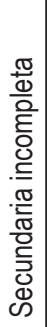 & 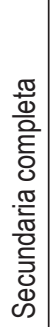 & $\begin{array}{l}\mathbb{U} \\
\frac{\mathbb{U}}{\bar{U}} \\
\stackrel{\mathbb{E}}{-}\end{array}$ & 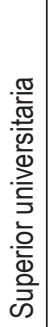 & 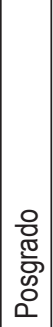 & $\begin{array}{l}\text { 응 } \\
\text { \& } \\
\text { 을 }\end{array}$ \\
\hline & 응 & $\stackrel{0}{0}$ & 4 & ס & 崩 & ปั & & & & & s & $=$ & & & & - \\
\hline
\end{tabular}




\begin{tabular}{|c|c|c|c|c|c|c|c|c|c|c|c|c|c|c|c|c|c|c|}
\hline & & & సิ̀ & & & $\begin{array}{l}8 \\
0 \\
0\end{array}$ & $\begin{array}{l}\frac{*}{6} \\
6 \\
0 \\
0\end{array}$ & $\begin{array}{l}\text { * } \\
x \\
\stackrel{m}{0} \\
0 \\
0\end{array}$ & 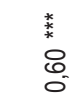 & 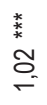 & 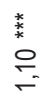 & 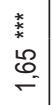 & $\begin{array}{l}* \\
* \\
* \\
0 \\
0\end{array}$ & $\begin{array}{l}* \\
* \\
8 \\
0 \\
0\end{array}$ & $\begin{array}{l}* \\
* \\
0 \\
0 \\
0\end{array}$ & & 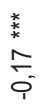 & 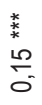 \\
\hline & & & ํㅗ․ & & & $\begin{array}{l}\mathscr{O} \\
\tilde{O}\end{array}$ & 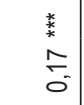 & $\begin{array}{l}\text { w } \\
* \\
\text { m } \\
0\end{array}$ & $\begin{array}{l}x \\
* \\
2 \\
20 \\
0 \\
0\end{array}$ & \begin{tabular}{l}
$\frac{x}{*}$ \\
\multirow{2}{*}{} \\
$\sigma$ \\
0
\end{tabular} & 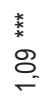 & 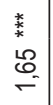 & \begin{tabular}{l}
$*$ \\
$*$ \\
\multirow{2}{*}{} \\
0 \\
0
\end{tabular} & $\begin{array}{l}* \\
* \\
8 \\
8 \\
0\end{array}$ & \begin{tabular}{l}
$*$ \\
$*$ \\
\multirow{2}{*}{} \\
$\stackrel{0}{0}$ \\
0
\end{tabular} & & $\begin{array}{l}* \\
* \\
0 \\
\frac{0}{0} \\
0 \\
1\end{array}$ & $\begin{array}{l}\text { * } \\
* \\
\infty \\
\vdots \\
0\end{array}$ \\
\hline & & & 욱 & & & $\begin{array}{l}8 \\
0\end{array}$ & \begin{tabular}{l} 
* \\
\multirow{2}{*}{} \\
\multirow{0}{*}{}
\end{tabular} & $\begin{array}{l}* \\
* \\
6 \\
m \\
0 \\
0\end{array}$ & 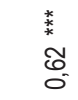 & $\begin{array}{l}\text { w } \\
x \\
\infty \\
o \\
0\end{array}$ & $\begin{array}{l}\frac{*}{*} \\
\stackrel{+}{ \pm} \\
=\end{array}$ & 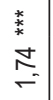 & $\begin{array}{l}* \\
* \\
0 \\
0 \\
0\end{array}$ & $\begin{array}{l}* \\
* \\
8 \\
8 \\
0\end{array}$ & 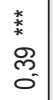 & & 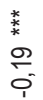 & 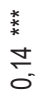 \\
\hline & & & ণ্ণ & & & $\begin{array}{l}\hat{0} \\
0\end{array}$ & \begin{tabular}{l}
$\frac{1}{*}$ \\
\multirow{2}{*}{} \\
0
\end{tabular} & 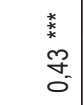 & $\begin{array}{l}\text { * } \\
* \\
\llcorner \\
0 \\
0\end{array}$ & 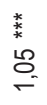 & $\begin{array}{l}\text { 絭 } \\
\Xi\end{array}$ & 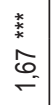 & 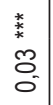 & $\begin{array}{l}* \\
* \\
8 \\
0 \\
0\end{array}$ & $\begin{array}{l}\frac{*}{*} \\
\bar{n} \\
0\end{array}$ & & $\begin{array}{l}\frac{*}{*} \\
\vdots \\
\vdots \\
\end{array}$ & $\begin{array}{l}\frac{*}{*} \\
\stackrel{0}{0} \\
\vdots \\
0\end{array}$ \\
\hline & 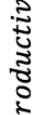 & 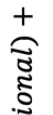 & నั & & & $\begin{array}{l}28 \\
0 \\
0\end{array}$ & $\begin{array}{l}\frac{*}{6} \\
\infty \\
0 \\
0\end{array}$ & \begin{tabular}{l}
$*$ \\
\multirow{2}{*}{} \\
$\mathbb{M}$ \\
0 \\
0
\end{tabular} & 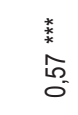 & $\begin{array}{l}\frac{k}{*} \\
x \\
\infty \\
0 \\
0\end{array}$ & \begin{tabular}{l} 
* \\
\multirow{2}{*}{} \\
$\stackrel{-}{-}$
\end{tabular} & $\begin{array}{l}\text { * } \\
* \\
\infty \\
\stackrel{0}{-} \\
-\end{array}$ & 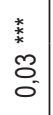 & $\begin{array}{l}* \\
8 \\
8 \\
0\end{array}$ & 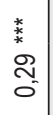 & & 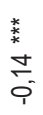 & $\begin{array}{l}\frac{*}{*} \\
\frac{3}{0} \\
\vdots\end{array}$ \\
\hline v & $\begin{array}{l}0 \\
0 \\
0 \\
0 \\
+ \\
0\end{array}$ & 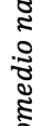 & ั. & & & $\begin{array}{l}20 \\
0 \\
0\end{array}$ & $\begin{array}{l}\frac{*}{*} \\
\frac{\infty}{0} \\
\frac{0}{0}\end{array}$ & 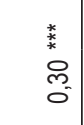 & 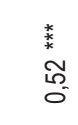 & \begin{tabular}{l} 
* \\
\multirow{2}{*}{} \\
$\hat{0}$ \\
0
\end{tabular} & 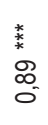 & $\begin{array}{l}\text { * } \\
* \\
\infty \\
m \\
-\end{array}$ & 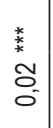 & \begin{tabular}{l}
$\frac{*}{*}$ \\
\multirow{2}{*}{} \\
8 \\
0
\end{tabular} & 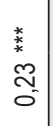 & & $\begin{array}{l}* \\
* \\
6 \\
5 \\
\vdots \\
i\end{array}$ & 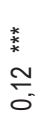 \\
\hline 我 & 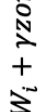 & 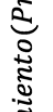 & 혹 & & & 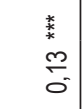 & $\begin{array}{l}\text { * } \\
\text { N } \\
\text { N } \\
0\end{array}$ & 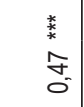 & $\begin{array}{l}\text { * } \\
* \\
8 \\
8 \\
0\end{array}$ & \begin{tabular}{l} 
w. \\
\multirow{2}{*}{} \\
$\hat{\sigma}$ \\
0
\end{tabular} & $\begin{array}{l}\underset{*}{*} \\
\infty \\
\infty \\
-\end{array}$ & \begin{tabular}{l}
$\frac{*}{*}$ \\
\multirow{2}{5}{} \\
5
\end{tabular} & $\begin{array}{l}\text { * } \\
* \\
\dddot{0} \\
0\end{array}$ & $\begin{array}{l}* \\
* \\
8 \\
8 \\
0\end{array}$ & $\begin{array}{l}* \\
* \\
* \\
\text { D } \\
0\end{array}$ & & $\begin{array}{l}* \\
* \\
0 \\
0 \\
0 \\
1\end{array}$ & $\begin{array}{l}\frac{*}{*} \\
\stackrel{0}{*}\end{array}$ \\
\hline$\frac{\pi}{2}$ & $\begin{array}{l}+ \\
\tilde{N} \\
\|\end{array}$ & 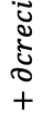 & 울 & & & \begin{tabular}{l}
$*$ \\
\multirow{2}{*}{} \\
0 \\
0
\end{tabular} & 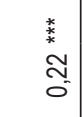 & $\begin{array}{l}\frac{x}{x} \\
\text { q } \\
q \\
0 \\
0\end{array}$ & 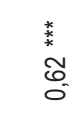 & 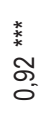 & 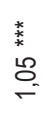 & 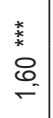 & \begin{tabular}{l}
$*$ \\
$*$ \\
\hdashline \\
0 \\
0
\end{tabular} & $\begin{array}{l}* \\
* \\
8 \\
8 \\
0\end{array}$ & 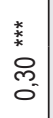 & & 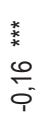 & 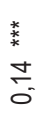 \\
\hline & 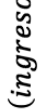 & & : & & & $\begin{array}{l}* \\
* \\
0 \\
0 \\
0\end{array}$ & \begin{tabular}{l}
$\stackrel{*}{*}$ \\
\multirow{2}{*}{} \\
$\vdots$ \\
0
\end{tabular} & $\begin{array}{l}\text { * } \\
x \\
o \\
0 \\
0\end{array}$ & 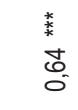 & 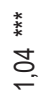 & $\begin{array}{l}\text { 絭 } \\
0 \\
\stackrel{0}{-}\end{array}$ & \begin{tabular}{l}
$\underset{*}{*}$ \\
\multirow{2}{*}{} \\
$\stackrel{-}{=}$
\end{tabular} & \begin{tabular}{l}
$*$ \\
$*$ \\
\multirow{2}{*}{} \\
$\dddot{0}$ \\
0
\end{tabular} & 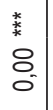 & \begin{tabular}{l}
$*$ \\
\multirow{2}{*}{} \\
\multirow{2}{*}{} \\
\multirow{2}{*}{} \\
0
\end{tabular} & & 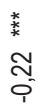 & $\begin{array}{l}\frac{*}{*} \\
\vdots \\
\vdots\end{array}$ \\
\hline & & & ্̊స & & & $\begin{array}{l}* \\
* \\
8 \\
0 \\
0\end{array}$ & 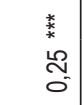 & 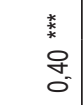 & 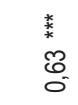 & $\begin{array}{l}w \\
w \\
\infty \\
\infty \\
\infty \\
0\end{array}$ & 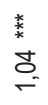 & \begin{tabular}{l}
$\frac{*}{*}$ \\
\multirow{6}{*}{} \\
-
\end{tabular} & \begin{tabular}{l}
$*$ \\
$*$ \\
\multirow{2}{*}{} \\
0 \\
0
\end{tabular} & $\begin{array}{l}* \\
* \\
8 \\
8 \\
0\end{array}$ & \begin{tabular}{l}
$*$ \\
$*$ \\
\multirow{2}{*}{} \\
$\tilde{m}$ \\
0
\end{tabular} & & 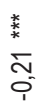 & $\begin{array}{l}\frac{*}{*} \\
\stackrel{*}{\sigma}\end{array}$ \\
\hline & & & స్రి & & $\simeq$ & $\begin{array}{l}* \\
* \\
m \\
\stackrel{*}{0}\end{array}$ & \begin{tabular}{l} 
* \\
\multirow{2}{*}{} \\
$\bar{m}$ \\
0
\end{tabular} & 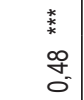 & 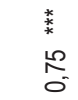 & 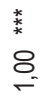 & $\begin{array}{l}\underset{*}{*} \\
\stackrel{2}{N} \\
\stackrel{2}{\longleftarrow}\end{array}$ & 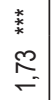 & $\begin{array}{l}\text { * } \\
* \\
2 \\
0 \\
0\end{array}$ & 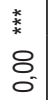 & 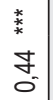 & & 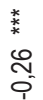 & $\begin{array}{l}\frac{*}{*} \\
\stackrel{*}{*} \\
\stackrel{0}{0}\end{array}$ \\
\hline & & & $\begin{array}{l}\frac{0}{0} \\
\frac{0}{\frac{0}{2}} \\
\frac{\pi}{>}\end{array}$ & 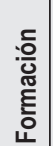 & 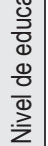 & 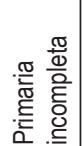 & 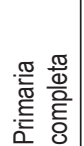 & 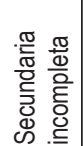 & 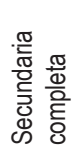 & 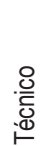 & 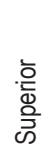 & $\begin{array}{l}\text { 음 } \\
\text { 늄 } \\
0 \\
0\end{array}$ & 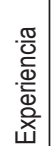 & 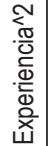 & $\begin{array}{l}\stackrel{\mathbb{N}}{\tilde{E}} \\
\stackrel{\text { 음 }}{1}\end{array}$ & 奇 & 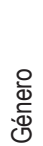 & 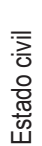 \\
\hline
\end{tabular}




\begin{tabular}{|c|c|c|c|c|c|c|c|c|}
\hline స్ & & & $\begin{array}{l}\frac{*}{*} \\
\vdots \\
\vdots \\
\end{array}$ & & 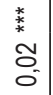 & 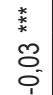 & $\begin{array}{l}\infty \\
\infty \\
\infty \\
\grave{\Sigma}\end{array}$ & 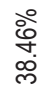 \\
\hline$\stackrel{\circ}{\frac{N}{2}}$ & & & $\begin{array}{l}\frac{*}{*} \\
E \\
\end{array}$ & & 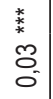 & \begin{tabular}{l}
$*$ \\
$*$ \\
\multirow{2}{*}{} \\
$\tilde{0}$ \\
1
\end{tabular} & 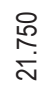 & $\begin{array}{l}\text { \%े } \\
\text { ळे } \\
\text { ले }\end{array}$ \\
\hline 옴 & & & $\begin{array}{l}* \\
* \\
* \\
0 \\
0 \\
0\end{array}$ & & \begin{tabular}{l}
$*$ \\
$*$ \\
\multirow{2}{*}{} \\
$\check{0}$ \\
0
\end{tabular} & \begin{tabular}{l}
$*$ \\
\multirow{2}{*}{} \\
$\widetilde{O}$ \\
0 \\
0
\end{tabular} & $\begin{array}{l}\bar{\delta} \\
\text { N̦ } \\
\text { N }\end{array}$ & $\begin{array}{l}\stackrel{0}{\circ} \\
\hat{\sigma} \\
0 \\
0\end{array}$ \\
\hline 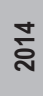 & & & 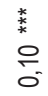 & & $\begin{array}{l}* \\
* \\
\dddot{0} \\
0 \\
0\end{array}$ & \begin{tabular}{l}
$*$ \\
$*$ \\
\multirow{2}{*}{} \\
0 \\
0
\end{tabular} & 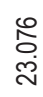 & 总 \\
\hline$\stackrel{m}{\sim}$ & & & $\begin{array}{l}\frac{*}{*} \\
\infty \\
0 \\
0\end{array}$ & & \begin{tabular}{l}
$*$ \\
$*$ \\
\multirow{2}{*}{} \\
0 \\
0
\end{tabular} & \begin{tabular}{l}
$*$ \\
\multirow{x}{*}{} \\
0 \\
0 \\
0
\end{tabular} & $\begin{array}{l}\text { 莳 } \\
\text { م. }\end{array}$ & 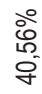 \\
\hline$\stackrel{\sim}{\sim}$ & & & \begin{tabular}{l} 
w \\
\multirow{2}{*}{} \\
$\mathbb{N}$ \\
0
\end{tabular} & & 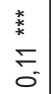 & \begin{tabular}{l}
$*$ \\
$*$ \\
\multirow{2}{*}{} \\
$\widetilde{O}$ \\
0
\end{tabular} & 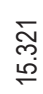 & $\begin{array}{l}\text { ¿े } \\
\text { ల్ల } \\
\text { ల్ }\end{array}$ \\
\hline$\overline{\text { స్ }}$ & & & 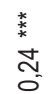 & & $\begin{array}{l}* \\
* \\
* \\
0 \\
0\end{array}$ & $\begin{array}{l}* \\
* \\
* \\
\widetilde{O} \\
0\end{array}$ & 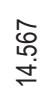 & $\begin{array}{l}\text { ০े } \\
\text { o } \\
\text { 心 }\end{array}$ \\
\hline 음 & & & $\frac{*}{*}$ & & $\begin{array}{l}* \\
* \\
2 \\
0 \\
0\end{array}$ & \begin{tabular}{l}
$*$ \\
\multirow{x}{*}{} \\
$\delta$ \\
0
\end{tabular} & 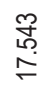 & 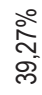 \\
\hline 유 & & & \begin{tabular}{l} 
* \\
\multirow{2}{*}{} \\
$\stackrel{2}{0}$ \\
0
\end{tabular} & & $\begin{array}{l}* \\
* \\
* \\
\vdots \\
0 \\
0\end{array}$ & 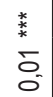 & $\begin{array}{l}\hat{\infty} \\
\underline{\omega} \\
0 \\
0\end{array}$ & 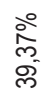 \\
\hline ర్లి & & & $\begin{array}{c}\frac{*}{*} \\
\bar{N} \\
\bar{\sigma}\end{array}$ & & $\begin{array}{l}* \\
* \\
0 \\
\sigma \\
0 \\
0\end{array}$ & 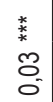 & $\begin{array}{l}\hat{\sigma} \\
\hat{\theta} \\
\underline{0}\end{array}$ & 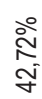 \\
\hline స్రి & & 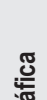 & \begin{tabular}{l} 
* \\
\multirow{2}{*}{} \\
0 \\
0 \\
0
\end{tabular} & & $\begin{array}{l}* \\
* \\
* \\
\vdots \\
0 \\
0\end{array}$ & $\stackrel{*}{8}$ & $\begin{array}{l}\stackrel{\infty}{\infty} \\
\stackrel{0}{6}\end{array}$ & $\begin{array}{l}\text { ه̊ } \\
\text { ఠ̊ } \\
\text { o }\end{array}$ \\
\hline $\begin{array}{l}\frac{0}{0} \\
\frac{0}{0} \\
\frac{0}{5}\end{array}$ & 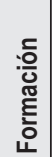 & 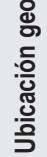 & $\underset{\mathbb{2}}{\stackrel{\mathbb{2}}{<}}$ & 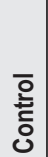 & 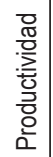 & 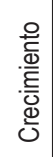 & $z$ & 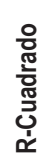 \\
\hline
\end{tabular}

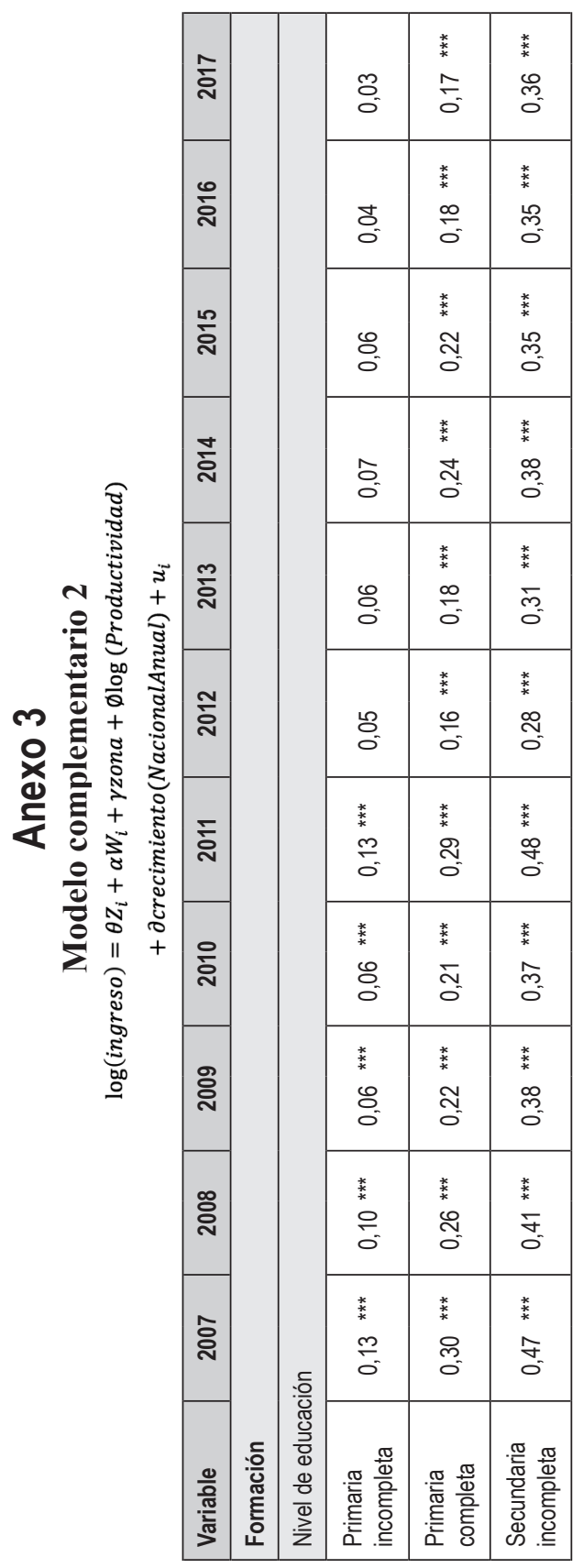




\begin{tabular}{|c|c|c|c|c|c|c|c|c|c|c|c|c|c|c|c|}
\hline స్ & & $\begin{array}{l}\frac{*}{*} \\
\overline{6} \\
\overline{0}\end{array}$ & 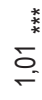 & 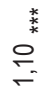 & 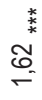 & 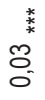 & $\begin{array}{l}8^{*} \\
8^{*}\end{array}$ & 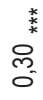 & & $\frac{{ }^{*}}{\infty^{*}}$ & $\frac{{ }^{*}}{\underbrace{*}}$ & & $\frac{\underbrace{*}}{2^{*}}$ & & 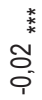 \\
\hline ஸั & & $\begin{array}{l}\text { w } \\
x \\
0 \\
0 \\
0\end{array}$ & 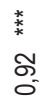 & \begin{tabular}{l} 
* \\
\multirow{2}{*}{} \\
$ㅇ$
\end{tabular} & 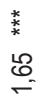 & $\begin{array}{l}\frac{*}{x} \\
0 \\
0 \\
0\end{array}$ & 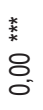 & \begin{tabular}{l} 
* \\
\multirow{2}{*}{} \\
$\stackrel{2}{N}$ \\
0
\end{tabular} & & 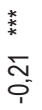 & $\begin{array}{l}\frac{*}{*}+ \\
\frac{1}{0} \\
\infty\end{array}$ & & \begin{tabular}{l}
\multirow{*}{*}{} \\
$\stackrel{*}{0}$
\end{tabular} & & \begin{tabular}{l}
$*$ \\
$*$ \\
\multirow{2}{*}{} \\
0 \\
0
\end{tabular} \\
\hline ஸn & & $\begin{array}{l}\frac{*}{*} \\
\overline{6} \\
\overline{0}\end{array}$ & $\begin{array}{l}* \\
* \\
* \\
\mathscr{8} \\
0 \\
0\end{array}$ & $\begin{array}{l}\stackrel{*}{*} \\
\stackrel{*}{\longleftarrow}\end{array}$ & 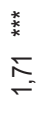 & \begin{tabular}{l}
$*$ \\
\multirow{2}{*}{} \\
0 \\
0 \\
0
\end{tabular} & 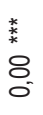 & 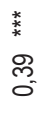 & & 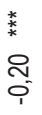 & $\begin{array}{l}\frac{*}{*}+ \\
\pm \\
\square\end{array}$ & & $\begin{array}{l}* \\
* \\
* \\
0 \\
0 \\
0\end{array}$ & & $\begin{array}{l}* \\
* \\
* \\
8 \\
0 \\
0\end{array}$ \\
\hline ণั & & $\begin{array}{l}\text { * } \\
* \\
\infty \\
\infty \\
0 \\
0\end{array}$ & \begin{tabular}{l} 
* \\
\multirow{2}{*}{} \\
$\infty$ \\
0 \\
0
\end{tabular} & 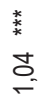 & 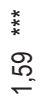 & 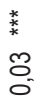 & $\begin{array}{l}\text { * } \\
8 \\
8 \\
0\end{array}$ & \begin{tabular}{l} 
* \\
\multirow{2}{*}{} \\
$\tilde{0}$ \\
0
\end{tabular} & & \begin{tabular}{l}
$*$ \\
\multirow{2}{*}{} \\
\multirow{1}{*}{}
\end{tabular} & 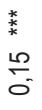 & & $\begin{array}{l}* \\
* \\
8 \\
8 \\
0\end{array}$ & & $\begin{array}{l}* \\
* \\
* \\
0 \\
0\end{array}$ \\
\hline ָั & & 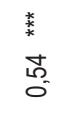 & $\begin{array}{l}\text { * } \\
* \\
\delta \\
0 \\
0\end{array}$ & 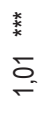 & 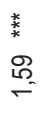 & 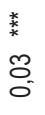 & 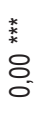 & 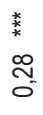 & & $\begin{array}{l}* \\
* \\
0 \\
\stackrel{*}{1}\end{array}$ & 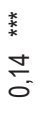 & & $\begin{array}{l}\text { * } \\
* \\
\frac{0}{0} \\
\vdots\end{array}$ & & $\begin{array}{l}* \\
* \\
* \\
0 \\
0 \\
0\end{array}$ \\
\hline ָั & & $\begin{array}{l}\frac{6}{6} \\
5 \\
0 \\
0\end{array}$ & $\begin{array}{l}* \\
* \\
0 \\
0 \\
0\end{array}$ & 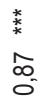 & 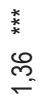 & \begin{tabular}{l} 
* \\
\multirow{2}{*}{} \\
$\dddot{0}$ \\
0
\end{tabular} & $\begin{array}{l}\frac{*}{*} \\
* \\
8 \\
0 \\
0\end{array}$ & 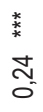 & & 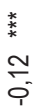 & 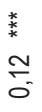 & & \begin{tabular}{l}
$\frac{*}{*}$ \\
\multirow{2}{*}{} \\
$\widetilde{N}$ \\
0
\end{tabular} & & 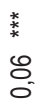 \\
\hline స్ & & $\begin{array}{l}\text { * } \\
* \\
0 \\
0 \\
0\end{array}$ & $\begin{array}{l}\stackrel{*}{*} \\
\stackrel{*}{*} \\
\stackrel{-}{-}\end{array}$ & 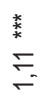 & 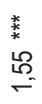 & 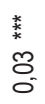 & $\begin{array}{l}\frac{*}{6} \\
8 \\
8 \\
0\end{array}$ & 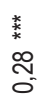 & & 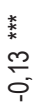 & $\begin{array}{l}\frac{*}{*} \\
\stackrel{+}{*}\end{array}$ & & 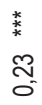 & & $\begin{array}{l}* \\
* \\
8 \\
0 \\
0\end{array}$ \\
\hline 웅 & & 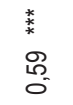 & $\begin{array}{l}\frac{*}{*} \\
* \\
\infty \\
0 \\
0\end{array}$ & $\begin{array}{l}\frac{*}{*} \\
* \\
8 \\
0 \\
0\end{array}$ & 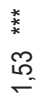 & 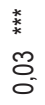 & 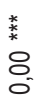 & \begin{tabular}{l}
$\frac{*}{*}$ \\
\multirow{2}{*}{} \\
$\tilde{0}$
\end{tabular} & & $\begin{array}{l}* \\
* \\
* \\
\infty \\
\vdots \\
1\end{array}$ & 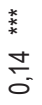 & & \begin{tabular}{l}
$\frac{*}{*}$ \\
\multirow{2}{*}{} \\
$\vdots$ \\
0
\end{tabular} & & 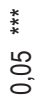 \\
\hline ণ্ণ & & $\begin{array}{l}\underset{*}{*} \\
\mathscr{0} \\
\ddot{0}\end{array}$ & \begin{tabular}{l}
$\frac{*}{*}$ \\
\multirow{0}{*}{} \\
-
\end{tabular} & 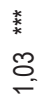 & 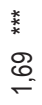 & 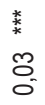 & $\begin{array}{l}\frac{*}{*} \\
* \\
8 \\
0\end{array}$ & 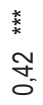 & & 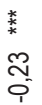 & 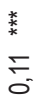 & & 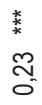 & & 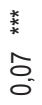 \\
\hline ஜ̊ & & $\begin{array}{l}* \\
* \\
6 \\
6 \\
0 \\
0\end{array}$ & 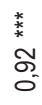 & 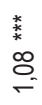 & 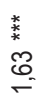 & 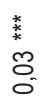 & 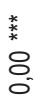 & 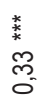 & & 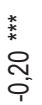 & $\begin{array}{l}\frac{*}{*} \\
\stackrel{+}{*} \\
\end{array}$ & & 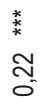 & & \begin{tabular}{l}
$\underset{*}{*}$ \\
\multirow{2}{0}{} \\
$\stackrel{0}{0}$
\end{tabular} \\
\hline స్రి & & $\begin{array}{l}\frac{*}{x} \\
\Re \\
0\end{array}$ & \begin{tabular}{l}
$*$ \\
\multirow{2}{*}{} \\
2 \\
0 \\
0
\end{tabular} & 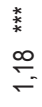 & 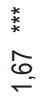 & \begin{tabular}{l} 
* \\
\multirow{2}{*}{} \\
0 \\
0 \\
0
\end{tabular} & $\begin{array}{l}\text { * } \\
\text { 8 } \\
8 \\
0\end{array}$ & 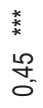 & & 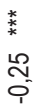 & $\frac{*}{E}$ & 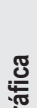 & \begin{tabular}{l} 
* \\
\multirow{2}{*}{} \\
$\widetilde{n}$ \\
$\tilde{0}$
\end{tabular} & & 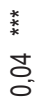 \\
\hline $\begin{array}{l}\frac{0}{0} \\
\frac{00}{\frac{\pi}{20}} \\
\frac{10}{7}\end{array}$ & $\begin{array}{l}\text { :0 } \\
\text { 음 } \\
\text { 혼 }\end{array}$ & 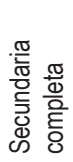 & 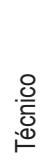 & $\begin{array}{l}\text { 흠 } \\
\text { 을 }\end{array}$ & $\begin{array}{l}\text { 음 } \\
\text { 휴 } \\
0 \\
0\end{array}$ & 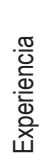 & 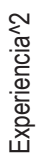 & $\begin{array}{l}\stackrel{\widetilde{E}}{E} \\
\text { 응 }\end{array}$ & 宽 & 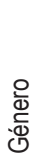 & 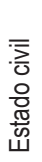 & 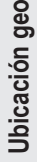 & 这 & $\begin{array}{l}\overline{0} \\
\text { 흠 }\end{array}$ & 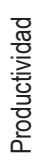 \\
\hline
\end{tabular}




\begin{tabular}{|c|c|c|c|c|}
\hline స్․ & & 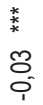 & $\begin{array}{l}\infty \\
0 \\
0 \\
\stackrel{亠}{N}\end{array}$ & $\begin{array}{l}\text { Oे } \\
\text { চ্ } \\
\text { চ্ }\end{array}$ \\
\hline 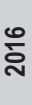 & & $\begin{array}{l}\text { * } \\
* \\
8 \\
0 \\
0\end{array}$ & 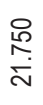 & $\begin{array}{l}\text { ০े } \\
\text { 今े }\end{array}$ \\
\hline$\stackrel{\text { ని }}{\frac{1}{2}}$ & & 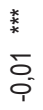 & 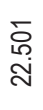 & $\begin{array}{l}\stackrel{0}{0} \\
60 \\
0 \\
0\end{array}$ \\
\hline ণ্ & & 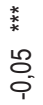 & 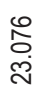 & $\underset{\infty}{\stackrel{\circ}{ }}$ \\
\hline$\stackrel{m}{\sim}$ & & 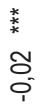 & $\begin{array}{l}\text { 专 } \\
\stackrel{0}{2}\end{array}$ & $\begin{array}{l}\text { సे } \\
\text { ঠ̊ }\end{array}$ \\
\hline$\stackrel{\sim}{\sim}$ & & 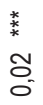 & $\begin{array}{l}\bar{\sim} \\
\text { ָூ } \\
\stackrel{\sigma}{\sigma}\end{array}$ & $\begin{array}{l}\text { ᄋे } \\
\text { ㅇ } \\
\text { ᄋ }\end{array}$ \\
\hline స్․ & & $\begin{array}{l}\text { * } \\
* \\
\delta \\
\delta\end{array}$ & $\begin{array}{l}\hat{b} \\
\stackrel{0}{+} \\
\forall\end{array}$ & $\begin{array}{l}0 \\
\circ \\
\infty \\
\text { 心 } \\
\text { m. }\end{array}$ \\
\hline 옹 & & 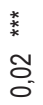 & $\begin{array}{l}\text { 莳 } \\
\stackrel{5}{\leftarrow}\end{array}$ & 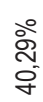 \\
\hline ণ্ণ & & 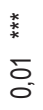 & $\begin{array}{l}\hat{\infty} \\
i \\
0 \\
0\end{array}$ & 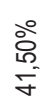 \\
\hline ્ֻస & & 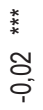 & \begin{tabular}{l}
$\hat{\varphi}$ \\
\multirow{0}{0}{} \\
0
\end{tabular} & $\begin{array}{l}\text { ণे } \\
\stackrel{0}{\mathcal{F}}\end{array}$ \\
\hline స్. & & 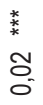 & $\begin{array}{l}\infty \\
\stackrel{\infty}{\infty} \\
\stackrel{0}{ }\end{array}$ & 犬े \\
\hline $\begin{array}{l}\frac{0}{0} \\
\frac{0}{\frac{\pi}{2}} \\
\frac{10}{5}\end{array}$ & 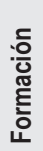 & 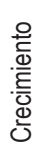 & $z$ & 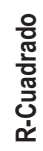 \\
\hline
\end{tabular}

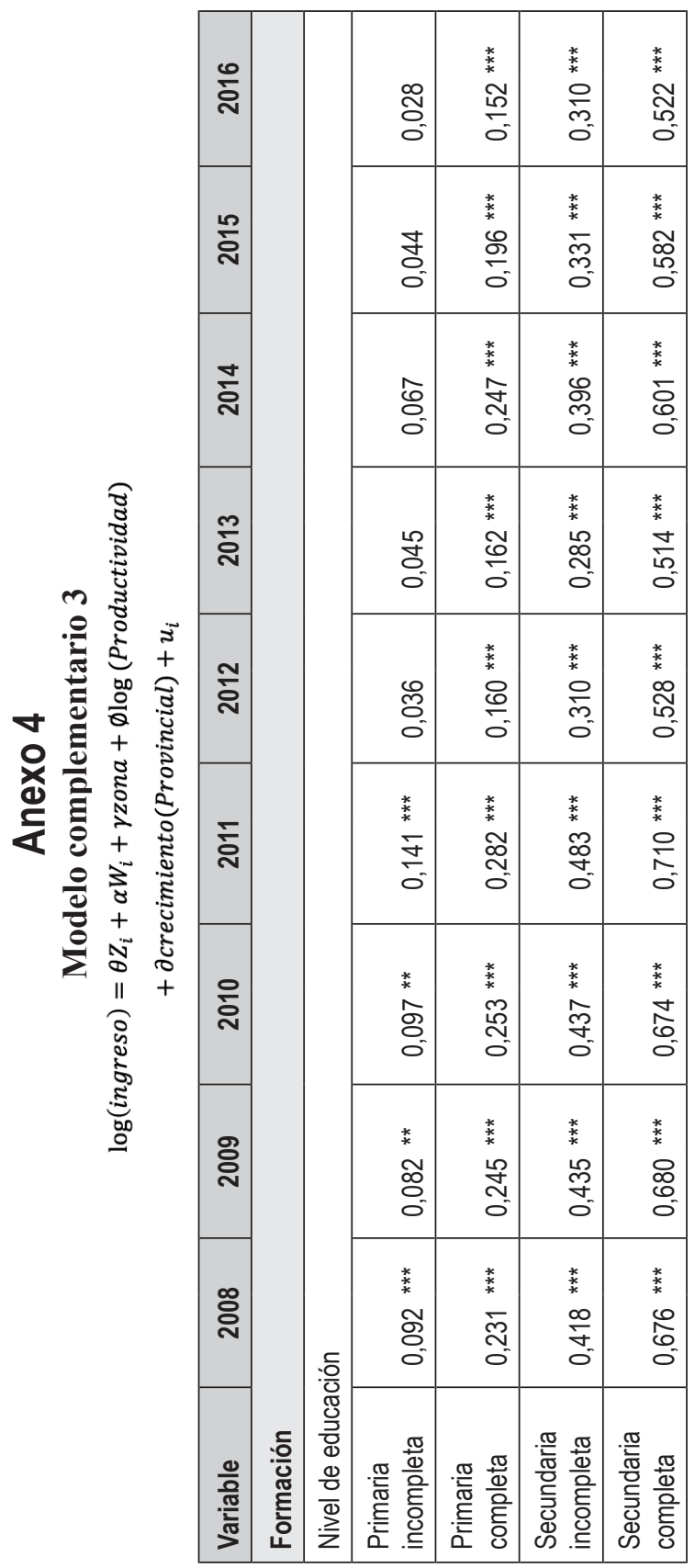




\begin{tabular}{|c|c|c|c|c|c|c|c|c|c|c|c|c|c|c|c|c|c|}
\hline$\stackrel{\circ}{\circ}$ & & 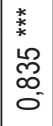 & 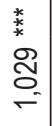 & \begin{tabular}{|l|}
$*$ \\
$*$ \\
$*$ \\
6 \\
0 \\
0 \\
-
\end{tabular} & 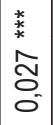 & \begin{tabular}{|l|}
$*$ \\
$*$ \\
$*$ \\
8 \\
8 \\
0 \\
0
\end{tabular} & 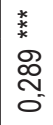 & & 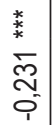 & \begin{tabular}{l}
$\frac{*}{*}$ \\
\multirow{2}{*}{} \\
$\stackrel{\infty}{\sigma}$ \\
$\tilde{\sigma}$
\end{tabular} & & \begin{tabular}{l}
$\frac{*}{*}$ \\
\multirow{2}{*}{} \\
$\stackrel{5}{\Xi}$ \\
0
\end{tabular} & & $\begin{array}{l}\text { * } \\
* \\
* \\
\cong \\
O \\
O \\
0\end{array}$ & $\begin{array}{l}0 \\
0 \\
0 \\
0 \\
1\end{array}$ & 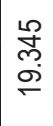 & $\begin{array}{l}\text { oे } \\
\text { ò } \\
\text { లే }\end{array}$ \\
\hline ని & & 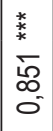 & 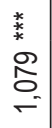 & $\begin{array}{l}* \\
* \\
* \\
\stackrel{2}{*} \\
\underset{-}{\infty} \\
\infty\end{array}$ & 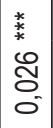 & \begin{tabular}{|l|}
$*$ \\
$*$ \\
$*$ \\
8 \\
8 \\
0 \\
0
\end{tabular} & 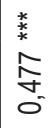 & & 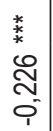 & 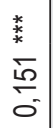 & & \begin{tabular}{l} 
* \\
\multirow{2}{*}{} \\
$\dddot{2}$ \\
0 \\
0 \\
0
\end{tabular} & & $\begin{array}{l}\text { v } \\
* \\
o \\
o \\
0 \\
0 \\
0\end{array}$ & 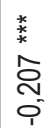 & 㑒 & 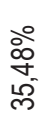 \\
\hline ণ্ড & & 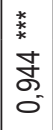 & 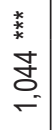 & 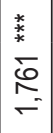 & 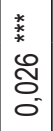 & \begin{tabular}{|l|}
$*$ \\
$*$ \\
$*$ \\
8 \\
8 \\
0 \\
0
\end{tabular} & \begin{tabular}{|l}
$*$ \\
$*$ \\
$*$ \\
0 \\
0 \\
0 \\
0 \\
0
\end{tabular} & & 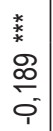 & 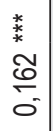 & & \begin{tabular}{l} 
* \\
\multirow{2}{*}{} \\
음 \\
$\vdots$
\end{tabular} & & 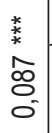 & $\begin{array}{l}\infty \\
\text { గ్ } \\
0 \\
0\end{array}$ & $\frac{\infty}{\sigma}$ & $\begin{array}{l}\text { ○े } \\
\text { ले } \\
\text { ஸे }\end{array}$ \\
\hline ণั & & 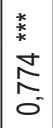 & 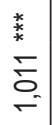 & $\begin{array}{l}* \\
* \\
* \\
\infty \\
\infty \\
\infty \\
\end{array}$ & $\begin{array}{l}* \\
* \\
* \\
* \\
2 \\
\mathcal{2} \\
0 \\
0\end{array}$ & \begin{tabular}{|l|}
$*$ \\
$*$ \\
$*$ \\
8 \\
8 \\
0 \\
0
\end{tabular} & 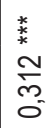 & & 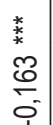 & \begin{tabular}{l}
$\frac{*}{*}$ \\
\multirow{*}{*}{} \\
\multirow{2}{\pm}{} \\
$\sigma^{\prime}$
\end{tabular} & & $\begin{array}{l}\text { * } \\
* \\
\infty \\
\infty \\
\vdots \\
0\end{array}$ & & 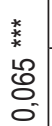 & 용 & $\frac{\mathscr{R}}{\stackrel{1}{ \pm}}$ & $\begin{array}{l}\text { ळे } \\
\text { ஸे } \\
\infty \\
\infty\end{array}$ \\
\hline ั. & & 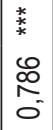 & $\begin{array}{l}* \\
* \\
* \\
0 \\
\sigma \\
\sigma \\
\sigma\end{array}$ & 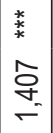 & 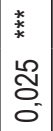 & \begin{tabular}{|l|}
$*$ \\
$*$ \\
$*$ \\
8 \\
8 \\
0 \\
0
\end{tabular} & 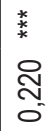 & & 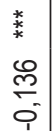 & $\begin{array}{l}\frac{*}{*} \\
* \\
\stackrel{+}{5} \\
5\end{array}$ & & 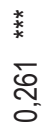 & & \begin{tabular}{l} 
v \\
$*$ \\
\multirow{2}{*}{} \\
$\cong$ \\
0 \\
0 \\
0
\end{tabular} & \begin{tabular}{l} 
* \\
\multirow{2}{*}{} \\
8 \\
$\frac{8}{0}$
\end{tabular} & 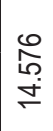 & $\begin{array}{l}\text { مे } \\
\text { ळ. } \\
\text { oे }\end{array}$ \\
\hline స్ & & 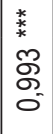 & \begin{tabular}{l}
$\mathfrak{*}_{*}^{*}$ \\
\multirow{*}{*}{} \\
$\stackrel{5}{\leftarrow}$
\end{tabular} & 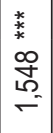 & $\begin{array}{l}* \\
* \\
* \\
0 \\
0 \\
0 \\
0\end{array}$ & $\begin{array}{l}* \\
* \\
* \\
8 \\
8 \\
8 \\
0\end{array}$ & 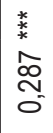 & & 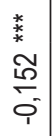 & 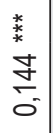 & & 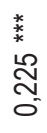 & & $\begin{array}{l}\text { * } \\
* \\
0 \\
0 \\
0 \\
0 \\
0\end{array}$ & $\begin{array}{l}\infty \\
0 \\
0 \\
\end{array}$ & 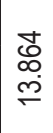 & 융 \\
\hline 윰 & & \begin{tabular}{l}
$*$ \\
$*$ \\
$*$ \\
\multirow{2}{*}{} \\
ठ \\
0 \\
0
\end{tabular} & 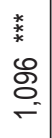 & 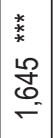 & $\begin{array}{l}* \\
* \\
* \\
\mathbb{Z} \\
0 \\
0\end{array}$ & $\begin{array}{l}* \\
* \\
* \\
8 \\
8 \\
0 \\
0\end{array}$ & $\begin{array}{l}* \\
* \\
* \\
8 \\
0 \\
0\end{array}$ & & 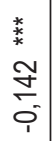 & 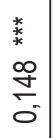 & & 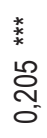 & & 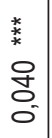 & $\frac{*}{2}$ & $\begin{array}{l}\infty \\
0 \\
0 \\
0 \\
0\end{array}$ & 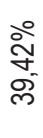 \\
\hline 옹 & & $\begin{array}{l}* \\
* \\
* \\
0 \\
0 \\
0 \\
-\end{array}$ & 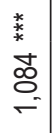 & 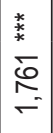 & $\begin{array}{l}* \\
* \\
* \\
\tilde{m} \\
0 \\
0\end{array}$ & $\begin{array}{l}* \\
* \\
* \\
8 \\
8 \\
0 \\
0\end{array}$ & \begin{tabular}{l}
$*$ \\
$*$ \\
$*$ \\
\multirow{2}{*}{} \\
\multirow{J}{*}{} \\
0
\end{tabular} & & 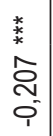 & $\begin{array}{l}\frac{*}{*} \\
* \\
8 \\
\stackrel{8}{0} \\
0\end{array}$ & & 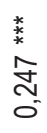 & & 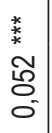 & 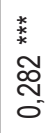 & $\begin{array}{l}10 \\
6 \\
5\end{array}$ & $\begin{array}{l}\text { مे } \\
\text { ळ. } \\
\text { o్ }\end{array}$ \\
\hline ণ্ & & 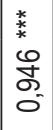 & 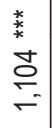 & $\begin{array}{c}* \\
* \\
* \\
\tilde{\sigma} \\
\underline{\sigma} \\
-\end{array}$ & $\begin{array}{c}* \\
* \\
* \\
\tilde{m} \\
0 \\
0\end{array}$ & \begin{tabular}{|l|}
$*$ \\
$*$ \\
$*$ \\
8 \\
8 \\
0 \\
0
\end{tabular} & 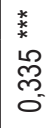 & & 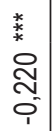 & 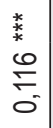 & 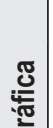 & 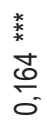 & & 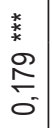 & 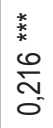 & 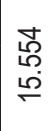 & $\begin{array}{l}\text { ○े } \\
80 \\
\text { ํ }\end{array}$ \\
\hline $\begin{array}{l}\frac{0}{0} \\
\frac{0}{\frac{\pi}{2}} \\
\frac{\pi}{>}\end{array}$ & 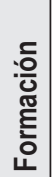 & $\begin{array}{l}\text { 을 } \\
\text { 엉 } \\
\text { iల }\end{array}$ & $\begin{array}{l}\text { 흔 } \\
\text { ळ } \\
\text { ڤ }\end{array}$ & $\begin{array}{l}\text { 음 } \\
\mathbb{0} \\
0 \\
0 \\
0\end{array}$ & 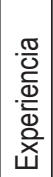 & 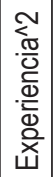 & $\begin{array}{l}\text { 을 } \\
\text { 응 } \\
\text { 으 }\end{array}$ & 甚 & 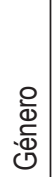 & 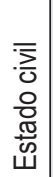 & 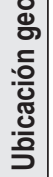 & $\stackrel{\mathbb{2}}{\stackrel{\mathbb{2}}{<}}$ & $\begin{array}{l}\overline{0} \\
\text { 는 } \\
\text { 이 }\end{array}$ & 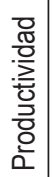 & 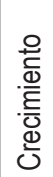 & $z$ & 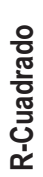 \\
\hline
\end{tabular}




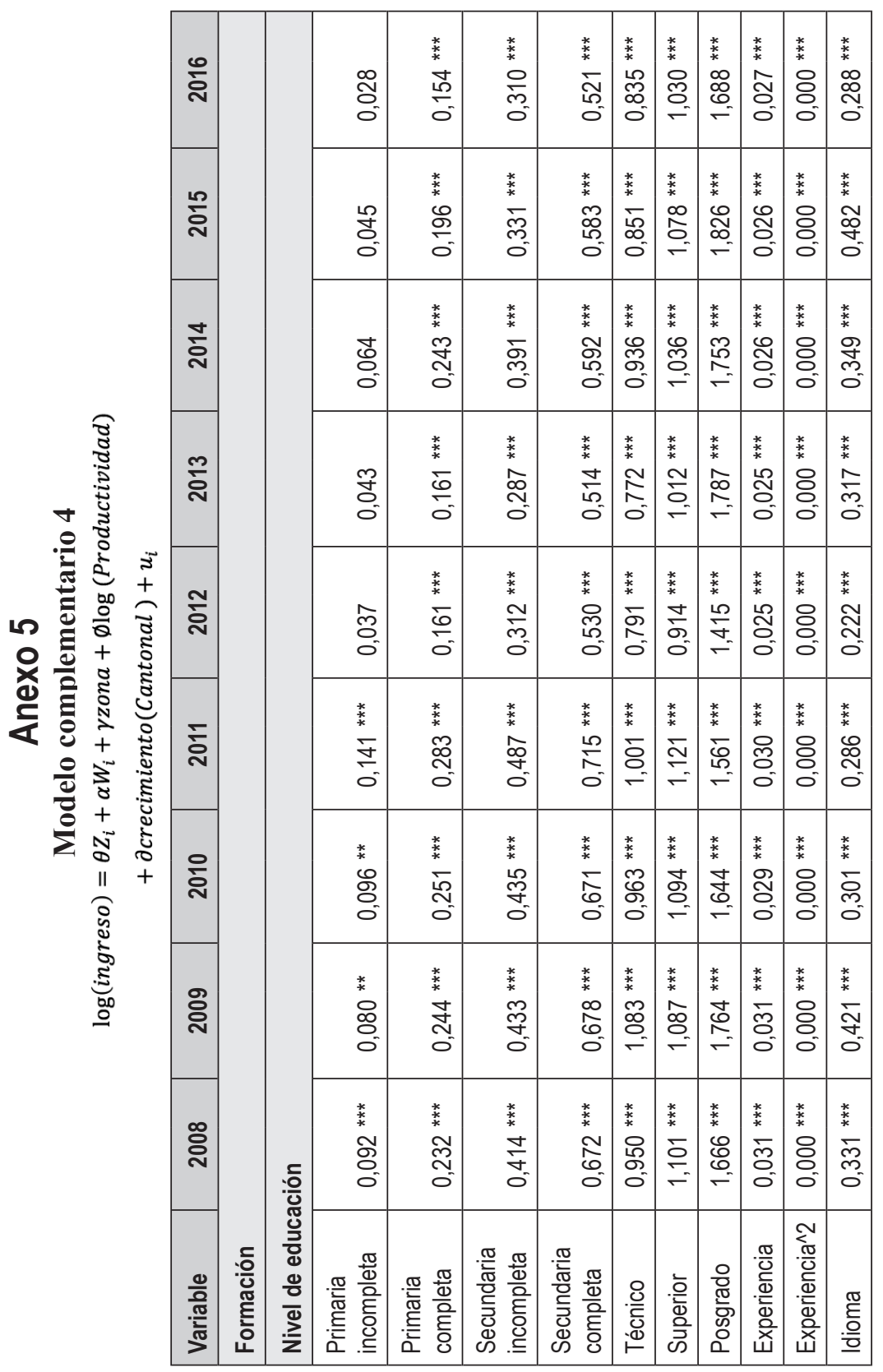




\begin{tabular}{|c|c|c|c|c|c|c|c|c|c|c|c|}
\hline 유 & & & 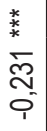 & 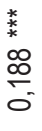 & & 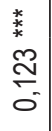 & & 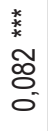 & 용 & $\frac{\widehat{\sigma}}{\stackrel{0}{\circ}}$ & 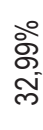 \\
\hline ำ & & & 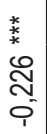 & 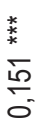 & & 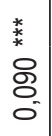 & & 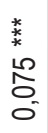 & శ్ల & $\begin{array}{l}\infty \\
\stackrel{\infty}{\infty} \\
\stackrel{0}{\circ}\end{array}$ & $\begin{array}{l}\stackrel{0}{\circ} \\
\stackrel{m}{n} \\
\stackrel{m}{m}\end{array}$ \\
\hline ষ্ণ & & & 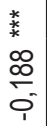 & 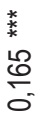 & & \begin{tabular}{l}
\multirow{*}{*}{} \\
$\stackrel{*}{*}$ \\
$\stackrel{5}{\sigma}$
\end{tabular} & & $\begin{array}{l}* \\
* \\
* \\
\mathscr{0} \\
0 \\
0 \\
0\end{array}$ & 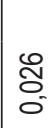 & $\begin{array}{l}\underset{m}{\tilde{D}} \\
\text { ס }\end{array}$ & 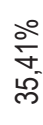 \\
\hline ঙ্ণ & & & 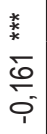 & 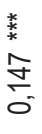 & & $\begin{array}{l}\frac{*}{*} \\
* \\
8 \\
\\
\\
\end{array}$ & & 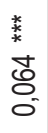 & ষ্ণ & $\begin{array}{l}\infty \\
\varnothing 8 \\
\dot{\leftarrow}\end{array}$ & $\begin{array}{l}\text { ¿े } \\
\infty \\
\infty\end{array}$ \\
\hline ָั & & & 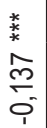 & 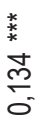 & & 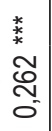 & & $\begin{array}{l}\text { * } \\
* \\
0 \\
0 \\
0 \\
0\end{array}$ & 守 & \begin{tabular}{l}
0 \\
$\stackrel{0}{L}$ \\
\multirow{\leftarrow}{*}{}
\end{tabular} & 六 \\
\hline స్ & & & 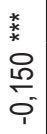 & 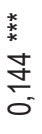 & & 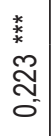 & & 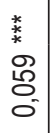 & 오 & $\begin{array}{l}\text { ర్ } \\
\infty \\
\text { m. }\end{array}$ & 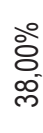 \\
\hline 웅 & & & 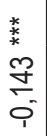 & 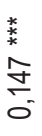 & & 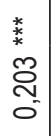 & & \begin{tabular}{l} 
* \\
$*$ \\
\multirow{2}{*}{} \\
\multirow{8}{0}{} \\
$0^{-}$
\end{tabular} & $\stackrel{\substack{* \\
* \\
*}}{\stackrel{2}{\tilde{\sigma}}}$ & $\begin{array}{l}\infty \\
\infty \\
0 \\
0 \\
0\end{array}$ & 令 \\
\hline 유 & & & 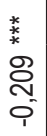 & $\begin{array}{l}\frac{*}{*} \\
* \\
\\
\\
\end{array}$ & & 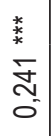 & & \begin{tabular}{l}
$*$ \\
$*$ \\
$*$ \\
\multirow{2}{*}{} \\
0 \\
0 \\
0
\end{tabular} & 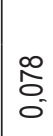 & $\begin{array}{l}\hat{b} \\
0 \\
0 \\
0\end{array}$ & $\frac{\text { Nे}}{\text { ब্ }}$ \\
\hline 。̊ & & & 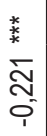 & 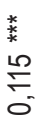 & 畩 & \begin{tabular}{l}
$\frac{*}{*}$ \\
\multirow{2}{*}{} \\
\\
0
\end{tabular} & & $\begin{array}{l}\text { * } \\
* \\
\infty \\
\infty \\
\vdots \\
\sigma\end{array}$ & \begin{tabular}{l}
$*$ \\
$*$ \\
$*$ \\
\multirow{2}{*}{} \\
$\tilde{m}$ \\
0
\end{tabular} & 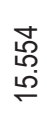 & 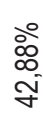 \\
\hline $\begin{array}{l}\frac{0}{0} \\
\frac{0}{\frac{0}{2}} \\
\frac{10}{>}\end{array}$ & 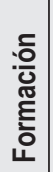 & 原 & $\begin{array}{l}\frac{O}{\mathbb{d}} \\
\stackrel{\leftarrow}{\mathbb{D}} \\
\end{array}$ & 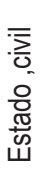 & 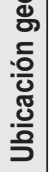 & 氶 & $\begin{array}{l}\overline{0} \\
\text { 는 } \\
\text { o }\end{array}$ & 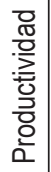 & 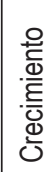 & $z$ & 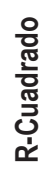 \\
\hline
\end{tabular}




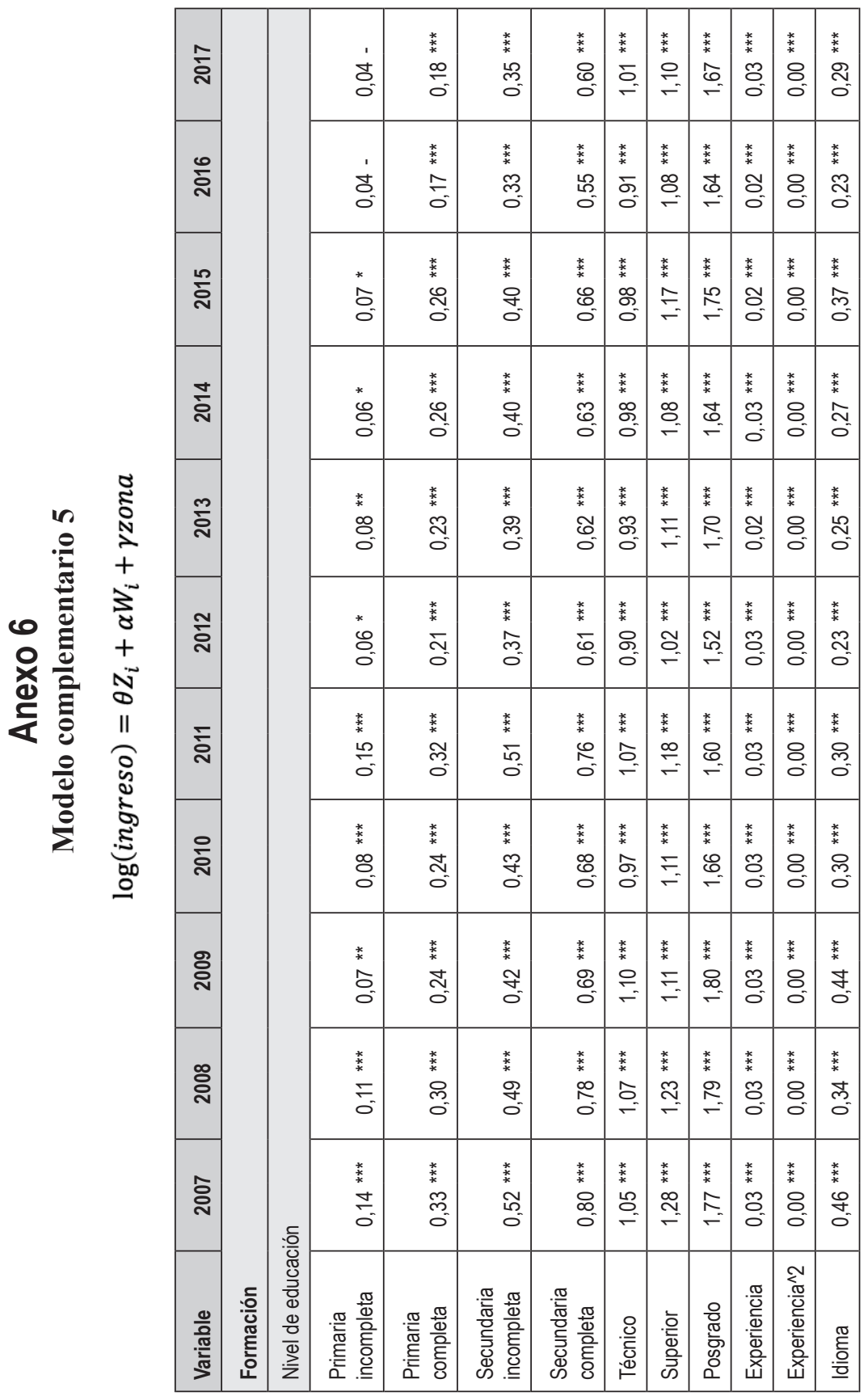




\begin{tabular}{|c|c|c|c|c|c|c|c|c|}
\hline స్ & & & 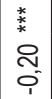 & 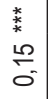 & & 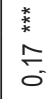 & $\begin{array}{l}\text { 莳 } \\
\text { 肙 }\end{array}$ & 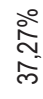 \\
\hline ஸั & & & \begin{tabular}{l}
$*$ \\
\multirow{2}{*}{} \\
$\widetilde{1}$ \\
$\tilde{1}$ \\
$\mathbf{1}$
\end{tabular} & $\begin{array}{l}\frac{*}{*} \\
\stackrel{2}{0} \\
\vdots\end{array}$ & & $\frac{\underset{*}{*}}{\stackrel{*}{*}}$ & 只 & $\begin{array}{l}\text { 今े } \\
\text { ले } \\
\text { लె }\end{array}$ \\
\hline$\stackrel{20}{\sim}$ & & & \begin{tabular}{c}
$*$ \\
\multirow{2}{*}{} \\
$\bar{N}$ \\
0 \\
\end{tabular} & 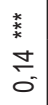 & & $\begin{array}{l}\text { * } \\
* \\
8 \\
8 \\
0 \\
0\end{array}$ & $\begin{array}{l}\text { + } \\
\text { id }\end{array}$ & ळे \\
\hline ণ্ণ & & & \begin{tabular}{l}
$*$ \\
\multirow{2}{*}{} \\
$\infty$ \\
$\vdots$ \\
\end{tabular} & \begin{tabular}{l}
$\frac{}{*}$ \\
\multirow{2}{*}{} \\
$\stackrel{0}{0}$ \\
0
\end{tabular} & & $\begin{array}{l}\frac{*}{*} \\
\stackrel{*}{\sigma} \\
\stackrel{0}{\sigma}\end{array}$ & $\begin{array}{l}\text { 옹 } \\
\infty \\
\text { ஸे }\end{array}$ & $\begin{array}{l}\text { مे } \\
\text { ळ́ }\end{array}$ \\
\hline$\stackrel{m}{\sim}$ & & & $\begin{array}{l}* \\
* \\
\infty \\
\vdots \\
0 \\
1\end{array}$ & \begin{tabular}{l}
$\stackrel{*}{*}$ \\
\multirow{2}{*}{} \\
$\stackrel{5}{\sigma}$
\end{tabular} & & 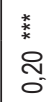 & $\begin{array}{l}\stackrel{\leftrightarrow}{\circ} \\
\stackrel{\infty}{\infty}\end{array}$ & $\begin{array}{l}\stackrel{\circ}{0} \\
\text { बे }\end{array}$ \\
\hline ণั & & & 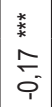 & 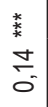 & & 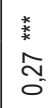 & $\begin{array}{l}\mathscr{E} \\
\mathscr{0} \\
6 \\
0\end{array}$ & $\begin{array}{l}\text { 今े } \\
\text { ه্ }\end{array}$ \\
\hline స్ণ & & & 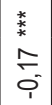 & $\begin{array}{l}* \\
* \\
6 \\
\vdots \\
0\end{array}$ & & 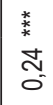 & $\frac{5}{i \infty}$ & $\begin{array}{l}\text { ᄋ̊ } \\
\text { ठ্் }\end{array}$ \\
\hline 웅 & & & 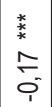 & $\begin{array}{l}\stackrel{*}{*} \\
\stackrel{+}{\sigma} \\
\check{0}\end{array}$ & & $\frac{\stackrel{*}{*}}{\stackrel{*}{*}}$ & $\begin{array}{l}\stackrel{m}{+} \\
\stackrel{\infty}{\leftarrow}\end{array}$ & $\begin{array}{l}\text { ᄋे } \\
\text { 心 }\end{array}$ \\
\hline 올 & & & 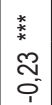 & 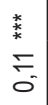 & & 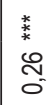 & 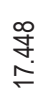 & $\begin{array}{l}\text { \&े } \\
\text { \& }\end{array}$ \\
\hline ণ̊ & & & 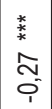 & 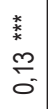 & & 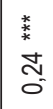 & $\begin{array}{l}\stackrel{N}{N} \\
\stackrel{*}{=}\end{array}$ & $\begin{array}{l}\text { 우 } \\
\text { م⿱ } \\
\text { 尺े }\end{array}$ \\
\hline ్ి & & & 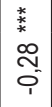 & $\begin{array}{l}\stackrel{*}{*} \\
\stackrel{2}{\simeq} \\
\vdots \\
-\end{array}$ & $\underset{\mathbb{J}}{\mathbb{W}}$ & 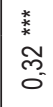 & $\frac{\text { S }}{\stackrel{9}{*}}$ & $\begin{array}{l}\stackrel{\circ}{\circ} \\
\text { 兽 }\end{array}$ \\
\hline $\begin{array}{l}\frac{0}{\frac{0}{0}} \\
\frac{\pi}{\frac{\pi}{5}} \\
\frac{10}{5}\end{array}$ & 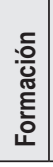 & $\overline{\bar{E}}$ & 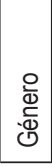 & 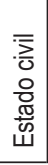 & 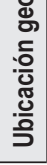 & 这 & $z$ & 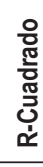 \\
\hline
\end{tabular}




\section{Anexo 7 \\ Pruebas posestimación modelo complementario 5 \\ Prueba de heterocedasticidad}

\begin{tabular}{|c|c|}
\hline \multicolumn{2}{|r|}{ Test de Breush-Pagan } \\
\hline & Ho: varianza constante \\
\hline \multicolumn{2}{|r|}{ Prob $>0.01$ No existe heterocedasticidad } \\
\hline \multirow[b]{2}{*}{2007} & $\operatorname{chi} 2(1)=0,84$ \\
\hline & Prob $>$ chi2 $=0,3595$ \\
\hline \multirow[b]{2}{*}{2008} & $\operatorname{chi} 2(1)=13,75$ \\
\hline & Prob $>$ chi2 $=0,0002$ \\
\hline \multirow[b]{2}{*}{2009} & $\operatorname{chi} 2(1)=36,20$ \\
\hline & Prob $>$ chi2 $=0,0000$ \\
\hline \multirow[b]{2}{*}{2010} & $\operatorname{chi} 2(1)=23,46$ \\
\hline & Prob $>$ chi2 $=0,0000$ \\
\hline \multirow[b]{2}{*}{2011} & $\operatorname{chi} 2(1)=16,51$ \\
\hline & Prob $>$ chi2 $=0,0000$ \\
\hline \multirow[b]{2}{*}{2012} & $\operatorname{chi} 2(1)=57,90$ \\
\hline & Prob $>$ chi2 $=0,0000$ \\
\hline \multirow[b]{2}{*}{2013} & $\operatorname{chi} 2(1)=0,00$ \\
\hline & Prob $>$ chi2 $=0,9672$ \\
\hline \multirow[b]{2}{*}{2014} & $\operatorname{chi} 2(1)=9,05$ \\
\hline & Prob $>$ chi2 $=0,0026$ \\
\hline \multirow[b]{2}{*}{2015} & $\operatorname{chi} 2(1)=1,30$ \\
\hline & Prob $>$ chi2 $=0,2533$ \\
\hline \multirow[b]{2}{*}{2016} & $\operatorname{chi} 2(1)=59,29$ \\
\hline & Prob> chi2 $=0,0000$ \\
\hline \multirow[b]{2}{*}{2017} & $\operatorname{chi} 2(1)=104,50$ \\
\hline & Prob $>$ chi2 $=0,0000$ \\
\hline
\end{tabular}

Nota. Elaboración en Stata, utilizando datos de ENEMDU 2007-2017. 


\section{Anexo 8}

\section{Prueba de normalidad gráfica}

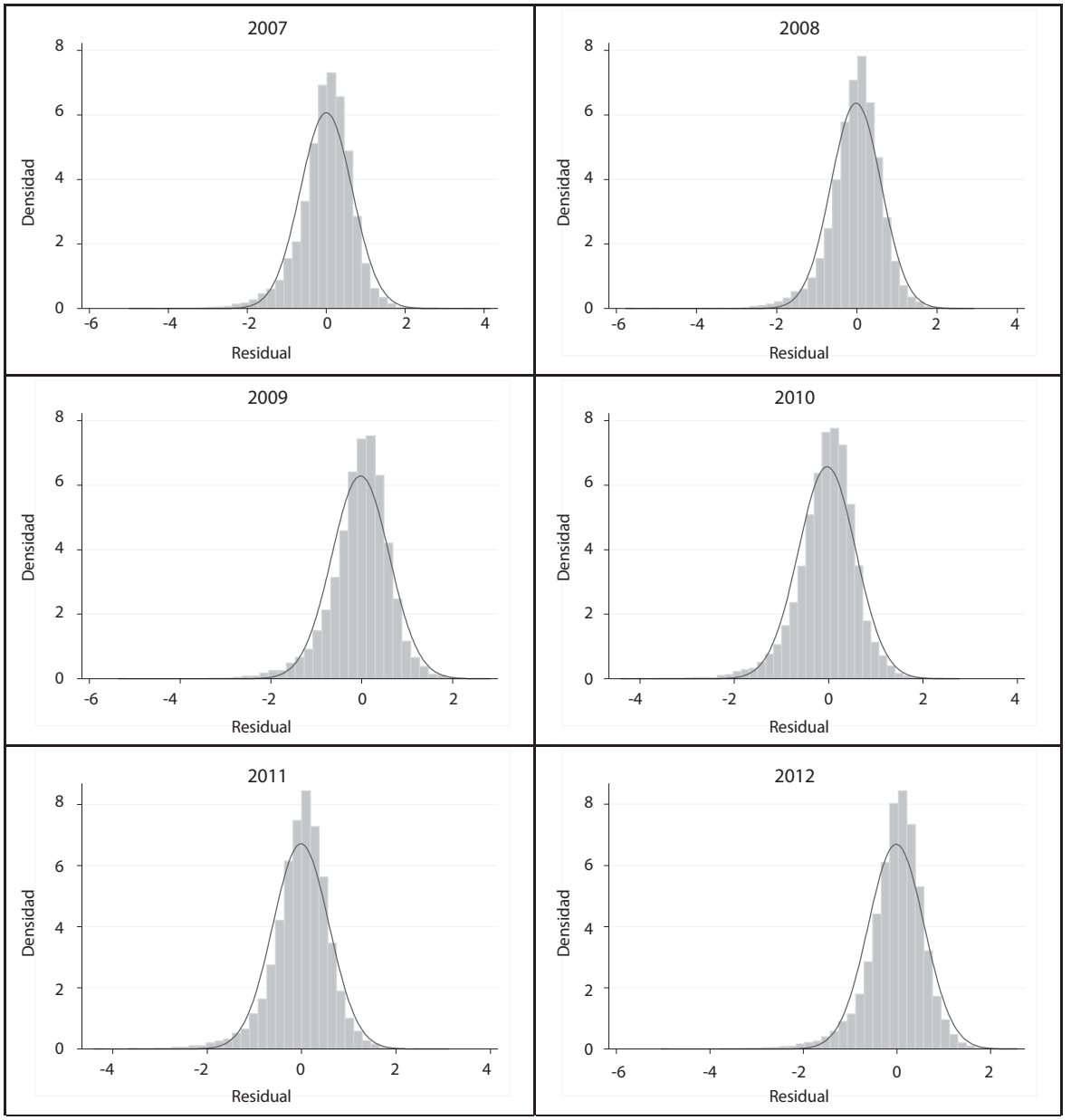


María Fernanda Lucero

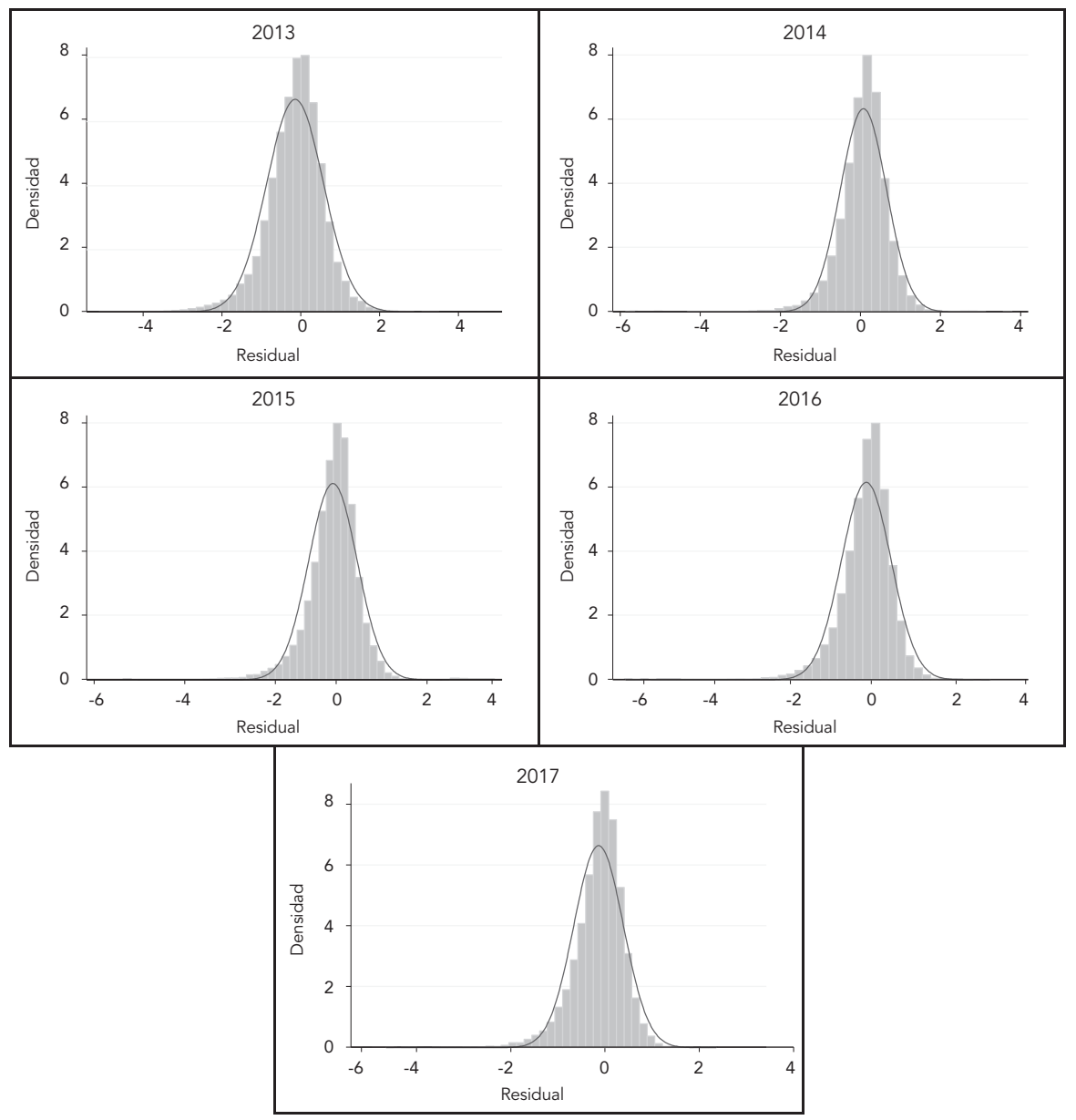

Nota. Elaboración en Stata, utilizando datos de ENEMDU 2007-2017. 